\title{
Precipitation Forecast Characteristics of Radar Data Assimilation Based on Precipitation Types
}

\author{
Jeong-Ho BAE ${ }^{1)}$ and Ki-Hong MIN ${ }^{2) *}$ \\ ${ }^{1)}$ National Typhoon Center, Korea Meteorological Administration, Seogwipo 63614, South Korea \\ ${ }^{2)}$ School of Earth System Sciences, Kyungpook National University, Daegu 41566, South Korea
}

\begin{abstract}
:
Radar observation data with high temporal and spatial resolution are used in the data assimilation experiment to improve precipitation forecast of a numerical model. The numerical model considered in this study is Weather Research and Forecasting (WRF) model with double-moment 6-class microphysics scheme (WDM6). We calculated radar equivalent reflectivity factor using higher resolution WRF and compared with radar observations in South Korea. To compare the precipitation forecast characteristics of three-dimensional variational (3D-Var) assimilation of radar data, four experiments are performed based on different precipitation types. Comparisons of the 24-h accumulated rainfall with Automatic Weather Station (AWS) data, Contoured Frequency by Altitude Diagram (CFAD), Time Height Cross Sections (THCS), and vertical hydrometeor profiles are used to evaluate and compare the accuracy. The model simulations are performed with and with-out 3D-VAR radar reflectivity, radial velocity and AWS assimilation for two mesoscale convective cases and two synoptic scale cases. The radar data assimilation experiment improved the location of precipitation area and rainfall intensity compared to the control run. Especially, for the two convective cases, simulating mesoscale convective system was greatly improved.
\end{abstract}

Key words: Radar, precipitation, 3D-Var, data assimilation, WRF 


\section{Introduction}

Convective precipitation forecast is one of the most challenging tasks in weather forecasting due to the nonlinear behaviour of the atmosphere. Numerical models are used to generate the high-resolution forecast of weather information. Improvement in the numerical weather prediction (NWP) generally means improvement in the physics and dynamics of the modeling system including model resolution [1,2] as well as improvement in the initial state (analysis) for the model [3-6]. In order to create the initial conditions for an NWP model (state of the atmosphere), in-situ observations are very crucial. One of the important sources of observations are sounding, Automatic Weather Station (AWS), and the remote sensing satellite data. In recent years, radial velocity and equivalent radar reflectivity from Doppler weather radars like Weather Surveillance Radar-1988 Doppler (WSR88D) have become important sources for higher resolution NWP models.

In cloud analysis schemes, radar data are the key measurements that can assimilate mesoscale features in NWP system $[7,8]$. For high-resolution NWP system through data assimilation, the radar reflectivity observations have en used to generate dynamically consistent and best analysis field (initial condition). In this methodology, the radar reflectivity observations are used to adjust hydrometeors, cloud temperature and cloud condensations [9]. Souto et al. [10] showed that the inclusion of cloud analysis improves the spatial distribution and the amount of precipitation forecast skill. Sun et al. [11], reports that radar data assimilation can improve the forecasting amount of precipitation but only up to 3-hour forecasts. In addition, digital filters and Newtonian nudging techniques are used to assimilate radar observations without considering the physical processes involved. Weygandt et al. [12] showed that the use of a diabatic digital filter initialization which adjusts latent heating based on radar reflectivity improved short-term forecasts.

During the last few years, for the high-resolution convective forecast, radar observations have been largely used in the data assimilation system in order to improve initial conditions [13]. Several assimilation methods have been developed for assimilating observed data into NWP models in convective scale. These assimilation systems include three-dimensional variational methods (3D-Var; [9, 14]) ; four-dimensional variational methods (4D-Var; [15-17] ) ; ensemble Kalman filter (EnKF; [18,19]) and hybrid method (3D/4D-Var + EnKF; [20-22]). These assimilation methods use observation operator to translate model variables (or control variables) on the model grid to the observed location. The previous study shown using those methods to prepare initial field improve the precipitation forecasts [17]. Many research communities and operational centers developed and tested the 3D-Var and 4D-Var for radar data assimilation with different observation operator and with different microphysics scheme [23]. Although the 4D-Var, EnKF and hybrid methods show great potential, these approaches still suffer from unaffordable computer costs for the high-resolution model at convection scale. So the cloud analysis and 3D-Var assimilation method are still widely used in research communities [24-26]. In a study by [27] found that 3D-Var analysis with the constraint is able to guide the assimilation process while adding the convective characteristics. Thus, the 3D-Var analysis with the constraint is more accurate when 
verified against an independent dataset. Many observing system simulation experiments (OSSE) have been conducted with real radar data and WRF 3D-Var assimilation system to examine the strengths and weaknesses of the system [21,28]. The WRF 3D-Var system has been evaluated and operationally implemented in the Korea Meteorological Administration (KMA; [29]). Many previous studies discuss the 3D-Var data assimilation system at convective scale along with their advantages and disadvantages, when radial wind and reflectivity are available [30-34]. Recently, using Vertically Integrated Liquid Water (VIL) calculated through a Mosaicked 3D radar reflectivity field for severe weather events, a pseudo water vapor and a pseudo in cloud potential temperature were produced and data assimilation was conducted. When simulating the Meiyu-Front cases, the predictability of the convective cloud simulation was improved [32]. In addition, in Italy, a study was conducted to compare predictability by applying WRF 3D-Var and 4D-Var to two flood cases. Through cases studie, it was reported that flood predictability was greatly improved when radar data assimilation was performed [33]. In Germany, an idialized experiment carried out on the simulation predictability of convective clouds in complex terrain using a regional-scale ensemble prediction model. Based on this, in realistic experiment, it was mentioned that the ability to simulate convective clouds by terrain was improved when the radar 3D-Var data assimilation was applied [34]. These studies have shown that assimilation of radar radial wind and reflectivity data in NWP system can improve short-range forecast skills.

Min et al. [35] evaluated WRF single moment 6-class (WSM6) and double-moment 6-class (WDM6) microphysics schemes with radar observations for 2011 summer monsoon and convective precipitation cases in Korea. This study showed that the accuracy of the WDM6 scheme is in better agreement with radar observations

Existing radar data assimilation studies were restricted to studies to improve the prediction of mesoscale precipitation, which develops rapidly in a short time at the local scale in the summer, and studies on improving the prediction of precipitation for extratropical cyclones or various synoptic precipitation phenomena are insufficient. Therefore, this study verified the predictability of three-dimensional variational data assimilation using meteorological radar observation data for mesoscale and synoptic scale precipitation phenomena, and analyzed the predictability of precipitation for each case to identify systematic characteristics.

In section 2 we describe the observations used, description of selected cases, the high resolution model configuration, the 3D-Var data assimilation method and evaluation of parameters; section 3 presents the results, and section 4 the summery and discussions. 


\section{Observations, Method, experiment set up and evaluation methodology}

\subsection{Observations:}

For objective comparison of WRF 3D-Var data assimilation we used three types of observations. These observations are from AWS, high resolution KMA radar reflectivity and radial velocity. The radar data were used after quality control (QC) and thinning. The fuzzy logic algorithm was used to remove anomalous propagation and non-meteorological echoes such as sea clutter, ground clutter and chaffs [36]. Total number of ten radar stations were used in the assimilation system. The data from AWS is also used in the assimilation system to update surface information because the radar stations are located on top of mountains to avoid beam blockage. The parameters from AWS data used in the WRF assimilation system are temperature, wind, air pressure, relative humidity. It should be noted that approximately 675 AWS stations are used in the assimilation. The 24-h AWS observed precipitation is used to compare with the model forecast rainfall. A domain area suitable for data assimilation on a local scale was established, and the detailed topography, observation site, and administrative districts of Korea are shown in Figure 1.

In addition, satellite based NASA Global Precipitation Measurement (GPM) gridded data (Level 3; The Integrated Multi-satellitE Retrievals for GPM, IMERG) with horizontal resolution of $0.1^{\circ} \times 0.1^{\circ}$ and time resolution of 30 minutes is used to analyze precipitation predictability of NWP. The GPM data has the advantage of supplementing the spatial limit of the rain gauge that can only observe precipitation on land to analyze the cumulative precipitation both over land and ocean.

\subsection{Description of selected cases}

In this study, we selected the cases based on whether there is Convective Available Potential Energy (CAPE) or Low-Level Jet stream (LLJ) to analyze the precipitation prediction characteristics of 3D-Var radar data assimilation. CAPE indicates thermal instability of the atmosphere, and those below 1,000 $\mathrm{m}^{2} \mathrm{~s}^{-2}$ are classified as weak instability, those between 1,000 to $2,500 \mathrm{~m}^{2} \mathrm{~s}^{-2}$ are moderate, and those above $2,500 \mathrm{~m}^{2} \mathrm{~s}^{-2}$ are high instability with possible convective cloud formation [37]. When a synoptic scale extratropical cyclone develops over the Yellow Sea, the air-sea interaction creates lowering of the central atmospheric pressure and an increase in pressure gradient force. Accordingly, strong winds of more than $12.5 \mathrm{~m} \mathrm{~s}^{-1}$ with a scale of several hundred to thousand $\mathrm{km}$ in the lower atmosphere below $850 \mathrm{hPa}$ are often accompanied with the system (Table 1; Figs. 2, $3)$.

Case 1 is of a local, heavy rainfall event in the western region of Korea due to rapid growth of convective clouds over the Yellow Sea, north of Changma front. Cold and dry air was introduced to the rear of the $500 \mathrm{hPa}$ trough passing through Manchuria. In addition, high-temperature and humid southerly winds caused by the North 
Pacific High were advected, leading to a highly unstable atmosphere with $1365 \mathrm{~m}^{2} \mathrm{~s}^{-2}$ of CAPE in Gwangju station. As a result, the convective clouds, which developed strongly at 1230 UTC on July 17, approached the Seoul metropolitan and central inland areas, and cumulative precipitation of $263 \mathrm{~mm}$ was observed during the case period with a strong hourly precipitation of $40 \mathrm{~mm} \mathrm{~h}^{-1}$ or more (Figs. 2a, b).

Case 2 shows a convective cloud emerged by the instability in the upper- and lower-level atmosphere in Gyeonggi-do, Gangwon-do, and Gyeongsang-do. The $500 \mathrm{hPa}$ trough located in Manchuria moved south to the Korean Peninsula. The surface air temperature increased significantly during the day with strong solar radiation, which resulted in more than $50{ }^{\circ} \mathrm{C}$ of a temperature difference between the $500 \mathrm{hPa}$ and the surface. This led to an extremely unstable atmosphere, and the CAPE of 1,243 $\mathrm{m}^{2} \mathrm{~s}^{-2}$ occurred in Osan. Strong convective clouds developed around the mid-Peninsula inland area, and the inland region was affected by local heavy rains of 50 $\mathrm{mm} \mathrm{h}^{-1}$ or more. Also, the accumulated precipitation of $20-60 \mathrm{~mm}$ was observed in Gangwon-do and Gyeongsang-do. Hail occurred due to the highly instable atmosphere, and farms in southern Gyeonggi-do, Gangwon-do, and northern Gyeongsangbuk-do suffered from severe damages (Figs. 2c, d).

Case 3 is a precipitation event caused by the influence of an extratropical cyclone. An extratropical cyclone in Huazhong, China, which occurred on May 2 at 0000 UTC, passed near the Shandong Peninsula on May 2 and entered the Yellow Sea, where it developed rapidly with the supply of hot and humid air from the ocean. Moreover, the cyclone was located in front of the strong $500 \mathrm{hPa}$ trough with cold air and the divergence zone of the $300 \mathrm{hPa}$ upper-level jet stream coincided with each other, leading to a rapid growth of the cyclone and the emergence of a wide LLJ area. As a result, a stratiform precipitation of less than $5 \mathrm{~mm} \mathrm{~h}^{-1}$ occurred throughout the Korean Peninsula. The observed AWS accumulated precipitation during the case period was over $80 \mathrm{~mm}$ in the central region and $220 \mathrm{~mm}$ in Jeju Island (Figs. 3a, b).

Case 4 is an event affected by an extratropical cyclone which developed along the monsoon front. The monsoon front located in Huanan, China moved northward to Huazhong, China by the upper-level trough. In addition, the upper-level jet divergence zone in North Korea rapidly developed the extratropical cyclone, which affected the Korean Peninsula. High temperature and humid air from Huanan, China and East China Sea ascended rapidly, resulting in a LLJ flowing into the Korean Peninsula. During the case period, accumulated precipitation of over $150 \mathrm{~mm}$ in the central region of the Korean Peninsula and $120 \mathrm{~mm}$ in the southern region were observed (Figs. 3c, d). As mentioned at the beginning of Section 2.2, we classified case 1 and 2 as mesoscale precipitation and case 3 and 4 as synoptic-scale precipitation events in this study. Furthermore, the mesoscale precipitation cases were named as Meso 1 and Meso 2, and the synoptic-scale precipitations as Synop 1 and Synop 2, respectively, for easier recognition. 


\subsection{WRF Model setup:}

We used a state-of-the-art limited area model, referred as Weather Research and Forecasting (WRF) Model version 3.7.1 [38]. The details of model configuration used in the present study are discussed in Table 2. All the forecasts were generated with three nested domains; the outer domain consisting of $301 \times 301$ grids with 13.5 $\mathrm{km}$ horizontal grid resolution in $\mathrm{x}$ - and y-direction, the inner domain consisting of $337 \mathrm{x} 364$ grids $(4.5 \mathrm{~km}$ horizontal grid resolution), and the innermost domain consisting of 640 x 820 (1.5 km horizontal grid resolution) grid points. The mother domain $(13.5 \mathrm{~km})$ is configured to allow large scale synoptic features to propagate appropriately over Korea. The number of vertical levels used is 60 , and the top of the model atmosphere is located at $50 \mathrm{hPa}$. The mother domain is configured to allow large-scale monsoon features over Korean Peninsula. The innermost domain of $1.5 \mathrm{~km}$ resolution is needed to account for the complexity of the local topography and to compare directly with the radar observations (Table 2; Fig. 1a). The initial conditions for the outer domain are provided by the National Center for Environmental Prediction (NCEP) Final analysis (FNL) data. The initial condition is enhanced by assimilation of local observations through the WRF 3D-Var schemes $[39,40]$. The 30-second datasets from United States Geological Survey (USGS) were used to create the surface boundary conditions such as model topography, land use, soil types, and monthly vegetation fraction. The initial, lower and lateral boundary conditions for the inner domains were obtained by interpolating the fields from the outer domain. We also used the WDM6 microphysics scheme in this study for both control run (CTRL) and 3DVar assimilation run (DA). The WDM6 allow for six types of hydrometeors - vapor mixing ratio $\left(q_{\text {vapor }}\right)$, rain mixing ratio $\left(q_{\text {rain }}\right)$, ice mixing ratio $\left(q_{\text {ice }}\right)$, cloud mixing ratio $\left(q_{\text {cloud }}\right)$ snow mixing ratio $\left(q_{\text {snow }}\right)$ and graupel mixing ratio $\left(q_{\text {graupel }}\right)$ to be predicted in the model [35].

\subsection{WRF 3D-Var Assimilation System}

The 3D-Var method in WRF data assimilation system is capable to assimilate all types of conventional observations as well as remote sensing observations [14]. The 3D-Var system combines the observations with background information on the model state and uses a linearized forecast model to ensure that the observations are given a dynamically realistic and consistency in the analysis field. In this study, we used incremental WRF 3D-Var data assimilation system [39,40]. The 3D-Var incremental system minimizes a scalar term called the cost function (or objective function, $J$ ) defined as a function of the analysis increment relative to the first gauss (background) using a linearized observation operator. The minimizations subjected to the constraint of observation uncertainty, the difference between the observations and the analysis projected to the observation space using the observations operator $(H)$. 


$$
J=J_{b}+J_{o}=\frac{1}{2} v^{T} v+\frac{1}{2}\left(\mathbf{d}-H^{\prime} \mathbf{U} v\right)^{T} \mathbf{R}^{-1}\left(\mathbf{d}-H^{\prime} \mathbf{U} v\right)
$$

The terms $J_{\mathrm{o}}$ and $J_{b}$ are the cost functions obtained from observation and background term, $\mathbf{R}$ is the observation error covariance matrix. The term $\mathbf{d}=\mathbf{y}_{o}-H\left(\mathbf{x}_{b}\right)$ is the innovation vector, which measures the departure of the observation $\mathbf{y}_{o}$ and the background $\mathbf{x}_{b}, H^{\prime}$ is the linearization of the nonlinear observation operator $H$. The term $v$ is the control variable, where $v=\mathbf{U}^{-1}\left(\mathbf{x}-\mathbf{x}_{b}\right), \mathbf{U}$ is the decomposition of the background error covariance $B$ under the constrain $\mathbf{B}=\mathbf{U U}^{\mathbf{T}}$. The covariance matrix for the regional background error statistics was calculated using NMC method [41] by taking 24-h and 12-h forecasts during the summer period (June, July and August) for the chosen domain with five control variables. These are the stream-function, unbalanced temperature, unbalanced surface pressure, unbalanced velocity potential, and pseudo-relative humidity. The minimization of cost is performed using conjugate gradient method. In all the four cases considered in this study (Table 1) hourly updated data assimilation cycle for 6-h have been made. In each assimilation cycle, observations from radar reflectivity, radial velocity and AWS observations are used during one hour period. In the case of the radar reflectivity data assimilation, it consists of a relative humidity operator and an assimilation algorithm for hydrometeor retrievals $[4,5,7,9,14,21,22]$. To provide a favorable environment for the formation of hydrometeors, the relative humidity of the numerical weather prediction model was adjusted to $75 \%$ if there was a radar reflectivity between $25 \mathrm{dBZ} \sim 30 \mathrm{dBZ}$ above the lifted condensation level (LCL), and was adjusted to $85 \%$ if it is more than $30 \mathrm{dBZ}$ [22]. The performance of this 3D-Var assimilation system on improving precipitation forecasts is tested using two convective cases in the year 2014, 2017 and two stratiform rain events in the year 2016. In the data assimilation system, it is also important to analyze the data input and the impact of those data in the analysis field. For each assimilation cycle approximately 8-9 stations were assimilated. In case of AWS data, an average of approximately 675 stations are used to assimilate temperature, pressure, and relative humidity in the assimilation system.

\subsection{Evaluation parameters}

For an objective comparison of the forecasts, we consider a number of evaluation parameters described below.

\section{a. The Contoured Frequency by Altitude Diagram (CFAD)}

The CFAD is a contour plot displaying the frequency distribution of reflectivity in an area of detectable echo volume at each vertical height in a single contour plot. Many studies show that the CFAD is a convenient tool to examine the characteristics of storms, especially for their temporal evolution [35]. The CFAD begins with a histogram calculation using a constant reflectivity bin width within a constant vertical volume [43]. 
The CFAD ignores the horizontal echo structure and summarizes the frequency distribution information in a single two dimensional plot. The mathematical descriptions of CFADs are discussed [44]. In this study, to plot CFAD diagram, the area was limited to a radius of $100 \mathrm{~km}$ from the observation point, considering the characteristics of the weather radar observation. To exploit the reflectivity information of an area where precipitation occurred, we used the vertical reflectivity information of the area where AWS precipitation of 0.1 $\mathrm{mm}$ or more was observed and the vertical interval is $250 \mathrm{~m}$. The histograms are normalized with the total number of points at each vertical level and the results are converted as a percentage value. The average reflectivity $\left(\overline{Z_{d B}}\right)$ and the average of the reflectivity factor in linear units $\left(\overline{Z_{d b}}\right.$ linear , in $\left.\mathrm{mm}^{-6} \mathrm{~m}^{-3}\right)$ are for each height is calculated as follows:

$$
\begin{gathered}
\overline{Z_{d b}}=\frac{1}{N_{k}} \sum_{i=1}^{n} d B Z_{i} \\
{\overline{Z_{d b}}}_{\text {linear }}=10 \times \log _{10}\left(\frac{1}{N_{k}} \sum_{i=1}^{n} 10^{0.1 \times d B Z_{i}}\right) .
\end{gathered}
$$

Here $\mathrm{N}$ is the total number of points at each height (level). In addition, we also calculated the cumulative reflectivity frequencies of the 25th, 50th, and 75th percentiles and include in each of the CFAD plots. 


\section{b. Time-Height Cross Sections (THCS)}

The time-height cross sections diagram is useful to identify the duration of the precipitation and the varying echo tops of the precipitating system. It is used to augment CFAD, which does not reveal time evolution characteristics of reflectivity (and so precipitation) that are related to phase errors in simulating any storm. We calculate the time-height cross sections of simulated reflectivity with 1-h temporal resolution where as radar observations with 20-min resolution (temporal). Also, all the observed datasets were vertically interpolated to $0.25 \mathrm{~km}$ from their native polar and the model datasets sigma vertical coordinates to same vertical resolution. The range is limited to approximately $100-\mathrm{km}$ radius. The Bright Band in the time-height cross section is represented by a line that stretches horizontally with higher reflectivity than the neighboring area. It is useful to identify the duration of the precipitation and the varying echo tops of the precipitating system. The time-height cross sections diagram is used to augment CFAD, which does not reveal time evolution characteristics of precipitation that are related to phase errors in simulating storms [35].

\section{c. Hydrometeor profile analysis}

We conducted the hydrometeor profile analysis to 1) analyze the change in humidity and the hydrometeor distribution in the initial dynamic field of the model through the radar data assimilation and 2) understand the microphysical processes of the clouds compared to the control run. With this, we anlayzed the changes in $q_{\text {vapor, }}$ $q_{\text {rain }}, q_{\text {ice }}, q_{\text {cloud }}, q_{\text {snow }}$, and $q_{\text {graupel }}$ due to the generation of clouds and precipitation during the prediction period of the cases, and investigated the cloud microphysical processes of the NWP model and the prediction characteristics of radar data assimilation. 


\section{Results}

\subsection{Analysis of the incremental initial field}

We analyzed the difference in the incremental initial fields between the data assimilation experiment and the control run by conducting the weather radar data assimilation. Through this analysis, we identified how much improvement was made in the initial field of the model compared to the control run (Figs. 4, 5).

In the initial field of Meso 1 (1430 UTC on July 17, 2014), convective clouds were in the Chungcheongdo region, and the radar reflectivity of more than $30 \mathrm{dBZ}$ were distributed at an altitude of $700 \mathrm{hPa}$ (about $3 \mathrm{~km}$ ) (Fig. 4a). The strong reflectivity in this region was applied to the model through the relative humidity operator, which led the increase in the vapor mixing ratio up to $3 \mathrm{~g} \mathrm{~kg}^{-1}$ or more, compared to the control run (Fig.4c). As the surrounding area was saturated, the rainwater mixing ratio increased based on the model temperature field classification (Fig. 4e). Strong convective clouds simulated in the Chungcheong-do region showed that the vertical upward airflow was increased by more than $1 \mathrm{~m} \mathrm{~s}^{-1}$ (Fig. 4d).

In the incremental initial field of Meso 2 (0130 UTC on June 01, 2017), there were convective clouds in the eastern Gyeonggi-do and the western region of Gangwon-do with a strong, vertical reflectivity of $20-35$ dBZ (Fig. 4e). In the regions where reflectivity exist, the water vapor and rainwater mixing ratio increased by 2 3 $\mathrm{g} \mathrm{kg}^{-1}$ and $0.6 \mathrm{~g} \mathrm{~kg}^{-1}$, respectively. Thus, the atmosphere became saturated, clouds were formed, and precipitation was simulated (Figs. 4f, 4g). A horizontal convergence was formed around the convective clouds simulated in the model and an ascending air increased. The region of cold air at $700 \mathrm{hPa}$ and the southerly winds created an unstable environment where convective clouds developed (Fig. 4h).

On the other hand, in the incremental initial field of Synop 1 (0500 UTC on 02 May 2016), a radar reflectivity of $15 \sim 35 \mathrm{dBZ}$ was distributed at an altitude of $700 \mathrm{hPa}$ (about $3 \mathrm{~km}$ ) as an extratropical cyclone passed through (Fig. 5a). Due to the radar reflectivity of more than $25 \mathrm{dBZ}$ located over the Yellow Sea, the water vapor mixing ratio increased by about $2 \mathrm{~g} \mathrm{~kg}^{-1}$. In the western inland of Korea, the water vapor mixing ratio decreased since no clouds were generated compared to the control run (Fig. 5b). Moreover, the rainwater mixing ratio was over-simulated in the control run, which reduced the ratio by $0.5 \sim 1.0 \mathrm{~g} \mathrm{~kg}^{-1}$ in waters off the Yellow Sea (Fig. 5c). The ascending air slightly increased in the region with increased vapor and rainwater mixing ratios. Throughout the domain, a clockwise rotating high pressure was formed, suppressing the oversimulation of the low pressure (Fig. 5d).

In the incremental initial field of Meso 2 (2300 UTC on June 30,2016), strong reflectivity up to $45 \mathrm{dBZ}$ was distributed at an altitude of $700 \mathrm{hPa}$ above the Yellow Sea as an extratropical cyclone developed over the approaching Changma front (Fig. 5e). This led to increase in the vapor and rainwater mixing ratios by $3 \mathrm{~g} \mathrm{~kg}^{-1}$ and $0.5 \sim 0.8 \mathrm{~g} \mathrm{~kg}^{-1}$ respectively, in the area with the strong reflectivity (Fig. 5f, 5g). Local convergence and cyclonic rotation was formed over the Yellow Sea and Pyongan-do, North Korea, while anticyclonic rotation was formed in the southern region and the southern sea of Korea (Fig. 5h). 
Overall, by carefully analyzing the changes in the initial fields of each case, we identified that the humidity and wind information of the initial fields were improved through the assimilation of weather radar data in areas where precipitation was not simulated at all or under simulated or where wind convergence should have occurred.

\subsection{Accumulated precipitation}

We compared the results of the control run with that of the assimilation run by using the cumulated precipitation information of AWS and GPM (Figs. 6, 7). The AWS cumulated precipitation of Meso 1 was up to $150 \mathrm{~mm}$ in the southern Gyeonggi-do (Fig. 6a). For the cumulated precipitation in the control run, a maximum of $40 \mathrm{~mm}$ was simulated in Jeollabuk-do and the convective precipitation was not well simulated (Fig. 6c). In contrast, mesoscale precipitation was simulated in the assimilation run and the cumulated precipitation of more than $150 \mathrm{~mm}$ was predicted in the mid-region of Korea similar to AWS (Fig. 6d). Precipitation over the ocean also showed improved simulation near the east coast (Figs. 6b, 6d).

During the period of Meso 2, the AWS cumulated precipitation was about $20 \sim 50 \mathrm{~mm}$ in Gangwon-do (Fig. 6e). The control run failed to simulate precipitation in the inland of Korea (Fig. 6g). However, improved results were found by simulating mesoscale precipitation in the inland of Korea, Western area of Gangwon-do, Gyeongsang-do, and the east coast through the radar data assimilation (Fig. 6h).

In Synop 1, the AWS cumulated precipitation of 50 - $80 \mathrm{~mm}$ was observed in Gyeonggi-do, Chungcheongnam-do, and the southern coast as an extratropical cyclone passed through the Korean Peninsula (Fig. 7a). In the control run, precipitation of up to $110 \mathrm{~mm}$ was accumulated on the west coast and in the metropolitan area, which was over-simulated compared to the AWS precipitation (Fig. 7c). In the assimilation run, the result was improved as the over-simulated precipitation on the west coast and the metropolitan area decreased by more than $40 \mathrm{~mm}$. However, the increased precipitation in the southern region was an overprediction (Fig. 8d). As for the precipitations occurred over the ocean, both the control and assimilation run simulated it well in the Yellow Sea, while both failed to simulate the heavy precipitation over the South Sea (Figs. 7b, 7d).

In Synop 2, a heavy precipitation occurred in the central and northern regions including the metropolitan area in the first half of the case, and in the southern regions in the second half, as an extratropical cyclone developed along the Changma front which passed through the Korean Peninsula. The AWS accumulated precipitation was more than $200 \mathrm{~mm}$ in the central region and $100 \sim 150 \mathrm{~mm}$ in the southern region (Fig. 7e). The control run was able to simulate the heavy precipitation in the first half of the case but was not able to simulate the southern region system during the second half. The accumulated precipitation from 130 to $150 \mathrm{~mm}$ was simulated in the control run (Fig. $7 \mathrm{~g}$ ). On the other hand, through the radar operator, the precipitation simulation was improved in the assimilation run with an increased cumulative precipitation by $20 \sim 40 \mathrm{~mm}$ in the central region, as well as in the southern region (Fig. 7h). The accumulated precipitation of over $150 \mathrm{~mm}$ at 
the southern coast was recorded in the GPM data, but neither the control run nor the assimilation run could simulate the heavy precipitation in the southern coast during the second half (Figs. 7f, 7h). The Synop 2 experiment showed that the effect of the radar data assimilation could not last longer than 12 hours.

\subsection{CFAD, THCS, and Hydrometeor profile}

We analyzed Meso 1 case based on the weather radar of Mt. Oseong (KSN; Fig. 1b). The reflectivity CFAD information of Mt. Oseong radar showed the hydrometeor growth from troposphere to an altitude of about 5.5 $\mathrm{km}$, and the decreased reflectivity at an altitude below $5.5 \mathrm{~km}$. The altitude of the melting layer was not clearly identified due to the localized mesoscale convective precipitation (Fig. 8a). The structure of CFAD was not clear in control run because the model could not simulate the precipitation properly (Fig. 8c). The assimilation run simulated the precipitation, which clearly showed that the hydrometeor grew from the upper to the lower atmospheric layer and that the increased reflectivity led to precipitation (Fig. 8e). The THCS showed reflectivity of $16 \sim 19 \mathrm{dBZ}$ at the beginning of the case, and $28 \sim 32 \mathrm{dBZ}$ was distributed when convective clouds approached the KSN radar site (Fig. 9a; 1500 UTC 17 to 0600 UTC 18 July 2014). The control run failed to properly simulate the precipitation, leading to the under-simulation of the reflectivity during the case period (Fig. 9c). In contrast, the heavy precipitation was simulated through the data assimilation, which in turn simulated a stronger reflectivity compared to control run (Fig. 9e). For the vertical hydrometeor profile, all hydrometeors were increased in the assimilation run (Fig. 10a). The ice and graupel mixing ratios increased above the melting layer, while the rainwater mixing ratio increased significantly below the melting layer, making the middle and upper atmospheric layers more humid compared to that of the control run.

As convective clouds developed rapidly in the metropolitan area in Meso 2 case, the CFAD was generated based on the reflectivity information recorded by the Mt. Gwanak radar (KWK; Fig. 1b). The frequency distribution of the reflectivity was high from the upper layer to an altitude of about $5 \mathrm{~km}$ and it decreased at the lower altitude (Fig. 8b). The CFAD of control run was not generated properly because the precipitation was not simulated in the model (Fig. 8d), while the assimilation run clearly showed the growth of the hydrometeor in the CFAD (Fig. 8f). In the THCS, columns of reflectivities ranging from 20 to $32 \mathrm{dBZ}$ were distributed from the lower atmosphere to an altitude of about $8 \mathrm{~km}$ (Fig. 9b; 0200 to 1500 UTC 01 June 2017). In the control run, there was no radar reflectivity in the lower atmosphere because the precipitation was not simulated (Fig. 9d). The DA run correctly simulated the precipitation at the beginning of the case and also simulated the strong reflectivity up to an altitude of $10 \mathrm{~km}$ (Fig. 9f). The vertical hydrometeor profile indicated all hydrometeors increased in the assimilation run. Similar to Meso 1, the ice and graupel mixing ratios increased above the melting layer and there was a noticeable increase in the rainwater mixing ratio below the melting layer, resulting in an overall humid atmosphere compared to the control run (Fig. 10b).

Recall that Synop 1 was a stratiform precipitation case caused by an extratropical cyclone passing through 
the Korean Peninsula. We analyzed the data based on the weather radar of KSN, focusing on the precipitation approaching from the west. The observed reflectivity information confirmed the growth of hydrometeors from the upper atmosphere to an altitude of about $5 \mathrm{~km}$, and the melting layer at an altitude around $4 \mathrm{~km}$, leading to the precipitation below the melting layer. The average reflectivity was $15 \mathrm{dBZ}$, which can be attributed to the weak precipitation of the extratropical cyclone over the large area (Fig. 11a). The structures of the CFAD was similar in both the control and the assimilation runs. However, the simulated precipitation decreased in the assimilation run, leading to a slightly decreased frequency distribution of the reflectivity around the middle and upper atmosphere above the melting layer (Figs. 11c, 11e). In the THCS from Mt. Oseong, the reflectivities of $20 \sim 30 \mathrm{dBZ}$ were distributed over the entire case period (Fig. 12a; 0600 UTC 02 to 0600 UTC 03 May 2016). Both the control and assimilation runs showed a similar structure of the THCS, but the assimilation run simulated the reflectivity of about $3 \sim 5 \mathrm{dBZ}$ lower than in the control run (Figs. 12c, 12e). The reason for the reduced reflectivity of the assimilation run can be attributed to two factors. One is that the radar reflectivity was observed to be less than $25 \mathrm{dBZ}$ for the most case period of Synop 1, and the relativity humidity operator was not properly applied when performing the data assimilation. The other is the atmosphere became drier compared to that in the control run since the vapor mixing ratio decreased. The vertical hydrometeor profile in the atmosphere was simulated in a similar way both in the control and assimilation runs, but overall, the hydrometeors decreased in the assimilation run (Fig. 13c).

Synop 2 was a case where precipitation occurred as an extratropical cyclone, which developed along the Changma front that passed through the Korean Peninsula. The analysis was conducted based on the weather radar of Mt. Gwangdeok (GDK; Fig. 1a). The observed reflectivity data confirmed the hydrometeor growth up to an altitude of about $5 \mathrm{~km}$ from the upper atmosphere, and also the existence of the melting layer at an altitude of around $4.5 \mathrm{~km}$. The average reflectivity was approximately $25 \mathrm{dBZ}$ in the lower atmosphere (Fig. 11b). Both the control and the assimilation runs showed the frequency distribution of the reflectivity of the upper and lower atmospheres higher than the observed reflectivity. The reflectivity increased from the melting layer at an altitude of about $5 \mathrm{~km}$, which led to the precipitation. The heavy blue solid line indicating the average reflectivity decreased by about $5 \mathrm{dBZ}$ in the assimilation run (Figs. 11d, 11f). In the THCS, the reflectivity up to $35 \mathrm{dBZ}$ was distributed until the middle of the case period due to heavy precipitation (Fig. 12b; 0000 UTC 01 to 0000 UTC 02 July 2016). A strong reflectivity of more than $35 \mathrm{dBZ}$ was distributed both in the control and assimilation runs. However, a relatively weak reflectivity was simulated in the assimilation run (Figs. 12d, 12f). Similar to the CFAD and the THCS information, the vertical hydrometeor was also reduced by the data assimilation (Fig. 13d).

\subsection{Verification of the precipitation}

To verify the predictability of precipitation simulation for WRF control and assimilation experiments, we 
conducted a quantitative precipitation comparison using approximately 680 nationwide AWS surface precipitation data. We calculated Fractional Skill Score (FSS), Equitable Threat Score (ETS), and Probability of Detection (POD) based on the precipitation intensity of $1 \mathrm{~mm} \mathrm{~h}^{-1}$ and $10 \mathrm{~mm} \mathrm{~h}^{-1}$ for the results obtained from the four case experiments (Table 3). In addition, we calculated pattern correlation to verify the spatial predictability of the model's precipitation forecasts (Fig. 14; Table 4). Meso 1 and Meso 2 were localized mesoscale convective precipitation cases. For all precipitation intensities of $1 \mathrm{~mm} \mathrm{~h}^{-1}$ and $10 \mathrm{~mm} \mathrm{~h}^{-1}$, the assimilation run improved results compared to the control run. However, for Synop 1 and Synop 2, where synoptic-scale induced precipitation occurred, the verification score in the assimilation run was not improved distinctively compared to the control run. Similarly, the spatial correlation of precipitation was significantly improved in the case of mesoscale convective precipitation (Table 4.2). Based on the verification results, it can be determined that the $3 \mathrm{D}-\mathrm{Var}$ assimilation using weather radar observation data is more effective in improving localized mesoscale precipitation events that the synoptic-scale driven precipitation events.

\section{Summary and Discussions:}

In this study, we analyzed the prediction characteristics of 3D-Var assimilation using weather radar observation data for four precipitation cases which occurred in Korea. The four cases selected for data assimilation runs were: (1) a mesoscale convective system which occurred on July 17, 2014; (2) a mesoscale precipitation that occurred on June 1, 2017; (3) a stratiform precipitation caused by an extratropical cyclone which occurred on May 2, 2016; and (4) a precipitation caused by a low pressure that developed along the monsoon rain band on July 1, 2016.

In Meso 1, the assimilation run with the radar data assimilation successfully simulated the precipitation that was not simulated in the control run. Analyzing the CFAD, THCS, and the vertical hydrometeor profile, the NWP model simulated stronger reflectivity than the observed data with the data assimilation. The stronger and intensive precipitation in the first half led to a dried atmosphere in the second half of the period, and the precipitation simulation ended earlier. An improved result was obtained in Meso 2 by simulating a localized mesoscale convective precipitation in the Seoul metropolitan area, Western area of Gangwon-do, and Gyeongsang-do, which was not simulated in the control run. Synop 1 was a synoptic-scale precipitation event caused by an extratropical cyclone passing through the Korean Peninsula in Spring. Compared with the observed reflectivity data, both the control and the assimilation run over-simulated the reflectivity. However, the assimilation experiment showed a similar precipitation pattern with that of the AWS accumulated precipitation. In Synop 2, heavy precipitation occurred in the central region during the first half of the period and in the southern region during the second half, as the cyclone developed along the Changma front passing through the Korean Peninsula. Although the control run failed to simulate the precipitation in the southern region during the second half, the assimilation run improved precipitation predictability in the southern region. Overall, the radar reflectivity 
through the data assimilation was over-simulated in all four cases through the CFAD, THCS, and vertical hydrometeor profile analyses.

To analyze the characteristics of precipitation simulation on the four cases, we conducted a quantitative verification using AWS accumulated precipitation information. In Meso 1 and 2, where the CAPE was high due to an unstable atmosphere, the predictability of precipitation was improved with the FSS, ETS, and POD increased by about 0.2 . As for the spatial pattern of precipitation, it was increased by 0.7 in Meso 1 , suggesting a great improvement in the spatial pattern predictability of precipitation. On the other hand, the spatial predictability in Meso 2 data assimilation was not significantly improved compared to the control simulation. Further, as shown in the verification results of FSS, ETS, and POD through the AWS accumulated precipitation, there was little improvement in Synop 1 and 2, which were synoptic-scale precipitation events with low-level jet stream, compared to the control run. The spatial pattern predictability of precipitation did not improve significantly either. Based on these results, it can be said that the precipitation predictability in cases of a localized mesoscale convective precipitation is significantly improved through the 3D-Var assimilation using the weather radar data.

This study showed that it is suitable to apply weather radar observation data, which has a high temporal and spatial resolution, to a numerical prediction model for simulating meteorological phenomena that can occur on a local scale. According to the results of this study, it was analyzed that the WRF model tends to over-simulate reflectivity compared to radar observations. Therefore, it is necessary to conduct further research for improving the precipitation predictability by adjusting the observation operator in the data assimilation or improving the cloud microphysical processes of responsible for generating hydrometeors that lead to precipitation. Lastly, studies with advanced data assimilation methods should be conducted to improve the NWP model forecast skills at multiple scales.

\section{Acknowledgments:}

This work was funded by the Korea Meteorological Administration Research and Development Programme under grant KMA2017-02410. This work was also supported by the National Research Foundation of Korea (NRF) funded by the Korea Ministry of Education (NRF-2019R1F1A1058620). 


\section{References:}

1. Roberts, N. and H. Lean, 2008: Scale-Selective Verification of Rainfall Accumulations from High-Resolution Forecasts of Convective Events. Mon. Wea. Rev., 136, 78-97, doi: 10.1175/2007MWR2123.1.

2. Chen, Y., H. Wang, J. Min, X. Huang, P. Minnis, R. Zhang, J. Haggerty, and R. Palikonda, 2015: Variational Assimilation of Cloud Liquid/Ice Water Path and Its Impact on NWP. J. Appl. Meteor. Climatol., 54, 18091825, doi: 10.1175/JAMC-D-14-0243.1.

3. Bouttier, F., 2009: Fine scale versus large scale data assimilation-A discussion. Fifth WMO Symposium on Data Assimilation, Melbourne, VIC, Australia, WMO World Weather Research Programme, 8 pp. [Available online

at https://www.researchgate.net/publication/268376800_Fine_scale_versus_large_scale_data_assimilation_a discussion.]

4. Wang, H., J. Sun, S. Fan, and X.-Y. Huang, 2013a: Indirect assimilation of radar reflectivity with WRF 3DVar and its impact on prediction of four summertime convective events. J. Appl. Meteor. Climatol., 52, 889902, doi:10.1175/JAMC-D-12-0120.1.

5. Wang, H., J. Sun, X. Zhang, X.-Y. Huang, and T. Auligné, 2013b: Radar data assimilation with WRF 4DVar. Part I: System development and preliminary testing. Mon. Wea. Rev., 141, 2224-2244, doi:10.1175/MWRD-12-00168.1.

6. Tai, S.-L., Y.-C. Liou, J. Sun, and S.-F. Chang, 2017: The devel-opment of a terrain-resolving scheme for the forward modeland its adjoint in the four-dimensional Variational Doppler Radar Analysis System (VDRAS). Mon. Wea. Rev., 145,289-306, doi:10.1175/MWR-D-16-0092.1.

7. Sun, J., and N. A. Crook, 1997: Dynamical and microphysical retrieval from doppler radar observations using a cloud modeland its adjoint. Part I: Model development and simulated data experiments. J. Atmos. Sci., 54, 1642-1661.

8. Sun, J., and N. A. Crook, 1998 : Dynamical and microphysical retrieval from Doppler radar observations using a cloud model and its adjoint. Part2: Retrieval experiments of an observed Florida convective storm. $J$. Atmos. Sci., 55, 835-852, doi:10.1175/1520-0469(1998)055<0835:DAMRFD>2.0.CO;2. 
9. Hu, M., M. Xue, and K. Brewster, 2006: 3DVAR and cloud analysiswith WSR-88D level-II data for the prediction of the FortWorth, Texas, tornadic thunderstorms. Part I: Cloud analysisand its impact. Mon. Wea. Rev., 134, 675-698, doi:10.1175/MWR3092.1.

10. Souto, M. J., C. F. Balseiro, V. Pérez-Muñuzuri, M. Xue, and K. Brewster, 2003: Impact of cloud analysis on numerical weather prediction in the Galician region of Spain. J. Appl. Meteor., 42, 129-140, doi:10.1175/1520-0450(2003)042<0129:IOCAON>2.0.CO;2.

11. Sun, J.-H., X.-L. Zhang, J. Wei, and S.-X. Zhao, 2005: A study on severe heavy rainfall in north China during the 1990s (in Chinese). Climatic Environ. Res, 10, 492-506, doi:10.3878/j.issn.1006-9585.2005.03.20

12. Weygandt, S. S., S. G. Benjamin, T. G. Smirnova, and J. M. Brown, 2008: Assimilation of radar reflectivity data using a diabatic digital filter within the Rapid Update Cycle. 12th Conf. on IOAS - AOLS, New Orleans, LA, Amer. Meteor. Soc., 8.4. [Available online at https://ams.confex.com/ams/pdfpapers/ 134081.pdf.]

13. Aksoy, A., D. C. Dowell, and C. Snyder, 2010: A multicase comparative assessment of the ensemble Kalman filter for assimilation of radar obser-vations. Part II: Short-range ensemble forecasts. Mon. Wea. Rev., 138, 1273-1292.

14. Xiao, Q. and J. Sun, 2007 : Multiple-radar data assimilation and short range quantitative precipitation forecasting of a squall line observed during IHOP 2002,” Mon. Wea. Rev., 135(10), 3381-3404.

15. Caya, A., J. Sun, and C. Snyder, 2005: A comparison between the 4DVAR and the ensemble Kalman filter techniques for radar data assimilation. Mon. Wea. Rev., 133, 3081-3094.

16. Wang, H., T. Auligné, and H. Morrison, 2012: Impact of Microphysics Scheme Complexity on the Propagation of Initial Perturbations. Mon. Wea. Rev., 140, 2287-2296,doi:10.1175/MWR-D-12-00005.1.

17. Sun, J., and H. Wang, 2013: WRF-ARW Variational Storm-Scale Data Assimilation: Current Capabilities and Future Developments. Adv. Meteorol, 2013, doi:10.1155/2013/815910

18. Dowell, D. C., L. J. Wicker, and C. Snyder, 2011: Ensemble kalman filter assimilation of radar observations of the 8 May 2003 Oklahoma city supercell: Influences of reflectivity observations onstorm-scale analyses. Mon. Wea. Rev., 139, 272-294, doi: 10.1175/2010MWR3438.1. 
19. Bick, T., C. Simmer, S. Trömel, Wapler, K., Hendricks Franssen, H.-J., Stephan, K., Blahak, U., Schraff, C., Reich, H., Zeng, Y. and R. Potthast, 2016: Assimilation of 3D radar reflectivities with an ensemble Kalman filter on the convective scale. Quart. J. Roy. Meteor. Soc., 142: 1490-1504. doi: 10.1002/qj.2751.

20. M. Zupanski, 2005: Maximum likelihood ensemble filter: Theoretical aspects. Mon. Wea. Rev., 133, 17101726. doi:10.1175/MWR2946.1

21. Gao, J. C. Fu, D. J. Stensrud, J. S. Kain, 2016: OSSEs for an Ensemble 3DVAR Data Assimilation System with Radar Observations of Convective Storms. Journal of the Atmospheric Sciences 73:6, 2403-2426.

22. Lee, J.-W., K.-H. Min, Y.-H. Lee, and G. Lee. 2020: X-Net-Based radar data assimilation study over the Seoul meteopolitan area. Remote Sens., 12(5), 893, doi: 10.3390/rs12050893.

23. Zhao, Q. Y., and Y. Jin 2008: High-resolution radar data assimilation for Hurricane Isabel (2003) at landfall, Bull. Amer. Meteorol. Soc., 89, 1355-1372.

24. Gao, J. and D. J. Stensrud, 2012 : Assimilation of reflectivity data in a convective-scale, cycled 3D-VAR framework with hydrometeor classification. J. Atmos. Sci., 69, 1054-1065.

25. Tong, M., and M. Xue, 2005: Ensemble Kalman filter assimilation of Doppler radar data with a compressible nonhydrostatic model: OSS experiments. Mon. Wea. Rev., 133, 1789-1807, doi:10.1175/MWR2898.1.

26. Lee Y.-H., and K.-H. Min, 2019: High-resolution modeling study of an isolated convective storm over Seoul Metropolitan area. Meteorol. Atmos. Phys., 131, 1549-1564.

27. Vendrasco, E. P., J. Sun., D. L. Herdies, and C. F. Angelis, 2016: Constraining a 3DVAR Radar Data Assimilation System with Large-Scale Analysis to Improve Short-Range Precipitation Forecasts. J. Appl. Meteorol. Climatol., 55, 673-690, doi:10.1175/1520-0493(1995)123<1941:TDKAME>2.0.CO;2

28. Sugimoto, S., N. A. Crook, J. Sun, Q. Xiao, and D. Barker, 2009: Assimilation of Doppler radar data with WRF 3DVAR: Evaluation of its potential benefits to quantitative precipitation forecasting through observing system simulation experiments. Mon. Wea. Rev., 137,4011-4029. 
29. Xiao, Q., Y. H. Kuo, J. Sun, W. C. Lee, E. Lim, Y. R. Guo, and D. M. Barker, 2005: Assimilation of doppler radar observations with a regional 3DVAR system: Impact of doppler velocities on forecasts of a heavy rainfall case. J. Appl. Meteor., 44, 768-788.

30. Johnson, A., X. Wang, J. Carley, L. Wicker, and C. Karstens, 2015: A Comparison of Multiscale GSIBased EnKF and 3DVar Data Assimilation Using Radar and Conventional Observations for Midlatitude Convective-Scale Precipitation Forecasts. Mon. Wea. Rev., 143, 3087-3108, doi: 10.1175/MWR-D-1400345.1.

31. Chang, S., Y. Liou, J. Sun, and S. Tai, 2016: The Implementation of the Ice-Phase Microphysical Process into a Four-Dimensional Variational Doppler Radar Analysis System (VDRAS) and Its Impact on Parameter Retrieval and Quantitative Precipitation Nowcasting. J. Atmos. Sci., 73, 1015-1038, doi: 10.1175/JAS-D-150184.1.

32. Lai A, J. Min, J. Gao, H. Ma, C. Cui, Y. Xiao, and Z. Wang, 2020: Assimilation of Radar Data, Pseudo Water Vapor, and Potential Temperature in a 3DVAR Framework for Improving Precipitation Forecast of Severe Weather Events. Atmosphere, 11(2), 182. https://doi.org/10.3390/atmos11020182

33. V. Mazzarella, I. Maiello, R. Ferretti, V. Capozzi, E. Picciotti, P. P. Alberoni, F. S. Marzano and G. Budillon, 2019: Reflectivity and velocity radar data assimilation for two flash flood events in central Italy, A comparison between 3D and 4D variational methods. Q. J. R. Meteorol Soc., 146, 348-366. https://doi.org/10.1002/qj.3679

34. Bachmann K., C. Keil, and G. C. Craig, 2020: Predictability of Deep Convection in Idealized and Operational Forecasts: Effects of Radar Data Assimilation, Orography, and Synoptic Weather Regime, Mon. Wea. Rev., 148(1), 63-81.

35. Min, K.-H., S. H., Choo, D. H. Lee and G. W., Lee, 2015 : Evaluation of WRF cloud microphysics scheme using radar observations, Wea. Forecasting., 30(6), 1571-1589.

36. Ye, B.-Y., G. Lee and H.-M. Park, 2015: Identification and removal of non-meteorological echoes in dualpolarization radar data based on a fuzzy logic algorithm. Adv. Atmos. Sci. 32, 1217-1230.

https://doi.org/10.1007/s00376-015-4092-0.

37. Das, M. K., S. Das, M. Rahman, 2015 : High-Impact Weather Events over the SAARC Region. Springer, 63-72. 
38. Skamarock, W. C., J. B. Klemp, J. Dudhia, D. O. Gill, D. M. Barker, M. G. Duda, X.-Y. Huang, W. Wang, J. G. Powers, 2008 : A Description of the Advanced Research WRF Version 3. 87-91.

39. Barker, D. M., W. Huang, Y. R. Guo, and Q. N. Xiao, 2004 : A three dimensional (3DVAR) data assimilation system for use with MM5: implementation and initial results, Mon. Wea. Rev., 132, 897-914.

40. Barker, D. M., and Coauthors, 2012: The Weather Research and Forecasting (WRF) Model's Community Variational/Ensemble Data Assimilation System: WRFDA. Bull. Amer. Meteor. Soc., 93, 831-843.

41. Parrish, D. F., and J. C. Derber, 1992: The National Meteorological Center's spectral statistical-interpolation analysis system. Mon. Wea. Rev., 120, 1747-1763, doi:10.1175/1520-0493(1992)120,1747:TNMCSS.2.0.CO;2.

42. Wang, J. -J., and L. D. Carey, 2005: Structure and evolution of an oceanic squall line during the South China Sea monsoon experiment. Mon. Wea. Rev., 133, 1544-1561.

43. Mecikalski, J. R., X. Li, L. D. Carey, and E. W. McCaul Jr., and T. A. Coleman, 2013: Regional Comparison of GOES Cloud-Top Properties and Radar Characteristics. Mon. Wea. Rev., 141, 55-74, doi:10.1175/MWR-D$12-00120.1$

44. Yuter, S. E., and R. A. Houze Jr.,: Three-Dimensional Kinematic and Microphysical Evoultion of Florida Cumulonimbus. Part 2: Frequency Distributions of Vertical Velocity, Reflectivity, and Differential Reflectivity. Mon. Wea. Rev., 123, 1941-1963, doi:10.1175/1520-0493(1995)123<1941:TDKAME>2.0.CO;2 
Table 1. Overview of precipitation cases.

\begin{tabular}{|c|c|c|c|c|c|}
\hline \multicolumn{2}{|c|}{ Case } & Case periods & Maximum CAPE & $\begin{array}{l}\text { Existence of } \\
\text { low level jet }\end{array}$ & Characteristics \\
\hline 1 & Meso 1 & $\begin{array}{l}\text { 2014.07. 17. } 1500 \mathrm{UTC} \\
2014.07 .18 .0600 \mathrm{UTC}\end{array}$ & $\begin{array}{c}\text { Gwang-ju : } 1365 \\
\text { (2014.07.18.0000UTC) }\end{array}$ & No & \multirow{2}{*}{$\begin{array}{l}\text { Mesoscale } \\
\text { precipitation }\end{array}$} \\
\hline 2 & Meso 2 & $\begin{array}{l}\text { 2017.06.01.0200 UTC } \\
2017.06 .01 .1500 \mathrm{UTC}\end{array}$ & $\begin{array}{c}\text { Osan : } 1243 \\
(2017.06 .01 .0000 \text { UTC) }\end{array}$ & No & \\
\hline 3 & Synop 1 & $\begin{array}{l}\text { 2016.05.02.0600 UTC } \\
2016.05 .03 .0600 \mathrm{UTC}\end{array}$ & $\begin{array}{c}\text { Gwang-ju : } 97 \\
\text { (2016.05.02.0600UTC) }\end{array}$ & Yes & \multirow{2}{*}{$\begin{array}{c}\text { Synoptic scale } \\
\text { embedded } \\
\text { precipitation }\end{array}$} \\
\hline 4 & Synop 2 & $\begin{array}{l}\text { 2016.07.01.0000 UTC } \\
\text { 2016.07.02.0000 UTC }\end{array}$ & $\begin{array}{c}\text { Osan : } 573 \\
(2016.07 .01 .0600 \mathrm{UTC})\end{array}$ & Yes & \\
\hline
\end{tabular}

Table 2. Selected configuration and parameterization schemes used in the Unified Model simulation.

\begin{tabular}{|c|c|}
\hline Category & Characteristics \\
\hline Horizontal resolution & $\begin{array}{l}13.5 \mathrm{~km}, 4.5 \mathrm{~km} \text { and } 1.5 \mathrm{~km} \\
\text { ( } 2 \text { nested grid / } 3 \text { domains) }\end{array}$ \\
\hline $\begin{array}{c}\text { \# of grids } \\
(\mathrm{d} 01|\mathrm{~d} 02| \mathrm{d} 03)\end{array}$ & $301 \times 301 \times 60 \quad|337 \times 364 \times 60 \quad| 640 \times 820 \times 60$ \\
\hline Vertical layer information & 60 sigma levels up to $50 \mathrm{hPa}$ \\
\hline Microphysics & WDM6 scheme \\
\hline Radiation & RRTM long / short wave scheme \\
\hline Cumulus parameterization & $\begin{array}{l}\text { Kain-Fritsch scheme } \\
\text { (domain } 3 \text { off) }\end{array}$ \\
\hline Planetary Boundary Layer & YSU scheme \\
\hline Surface & Revised MM5 Monin-Obukhov Similarity scheme \\
\hline Land surface model & RUC LSM scheme \\
\hline
\end{tabular}


Table 3. Results of precipitation verification for cases.

\begin{tabular}{|c|c|c|c|c|c|}
\hline \multirow{2}{*}{\multicolumn{2}{|c|}{ Case rainrate }} & \multicolumn{2}{|c|}{$1 \mathrm{~mm}$} & \multicolumn{2}{|c|}{$10 \mathrm{~mm}$} \\
\hline & & \multirow{2}{*}{$\begin{array}{c}\text { CTRL } \\
0.180\end{array}$} & \multirow{2}{*}{$\begin{array}{c}\text { DA } \\
0.328\end{array}$} & \multirow{2}{*}{$\frac{\text { CTRL }}{0.052}$} & \multirow{2}{*}{$\begin{array}{c}\text { DA } \\
0.235\end{array}$} \\
\hline \multirow{3}{*}{ Meso 1} & FSS & & & & \\
\hline & ETS & -0.002 & 0.029 & -0.003 & 0.013 \\
\hline & POD & 0.030 & 0.180 & 0 & 0.107 \\
\hline \multirow{3}{*}{ Meso 2} & FSS & 0.144 & 0.278 & 0.081 & 0.194 \\
\hline & ETS & 0.043 & 0.097 & 0.003 & 0.078 \\
\hline & POD & 0.109 & 0.196 & 0.017 & 0.184 \\
\hline \multirow{3}{*}{ Synop 1} & FSS & 0.637 & 0.709 & 0.363 & 0.401 \\
\hline & ETS & 0.086 & 0.191 & 0.051 & 0.059 \\
\hline & POD & 0.481 & 0.549 & 0.269 & 0.284 \\
\hline \multirow{3}{*}{ Synop 2} & FSS & 0.644 & 0.602 & 0.529 & 0.481 \\
\hline & ETS & 0.146 & 0.147 & 0.127 & 0.132 \\
\hline & POD & 0.594 & 0.569 & 0.284 & 0.269 \\
\hline
\end{tabular}

Table 4. Results of precipitation pattern verification for cases.

\begin{tabular}{|c|c|c|}
\hline \multirow{2}{*}{ Sase } & \multicolumn{2}{|c|}{ Pattern correlation } \\
\cline { 2 - 3 } & CTRL & DA \\
\hline Meso 1 & -0.093 & 0.728 \\
\hline Meso 2 & 0.147 & 0.253 \\
\hline Synop 1 & 0.614 & 0.649 \\
\hline Synop 2 & 0.484 & 0.507 \\
\hline
\end{tabular}




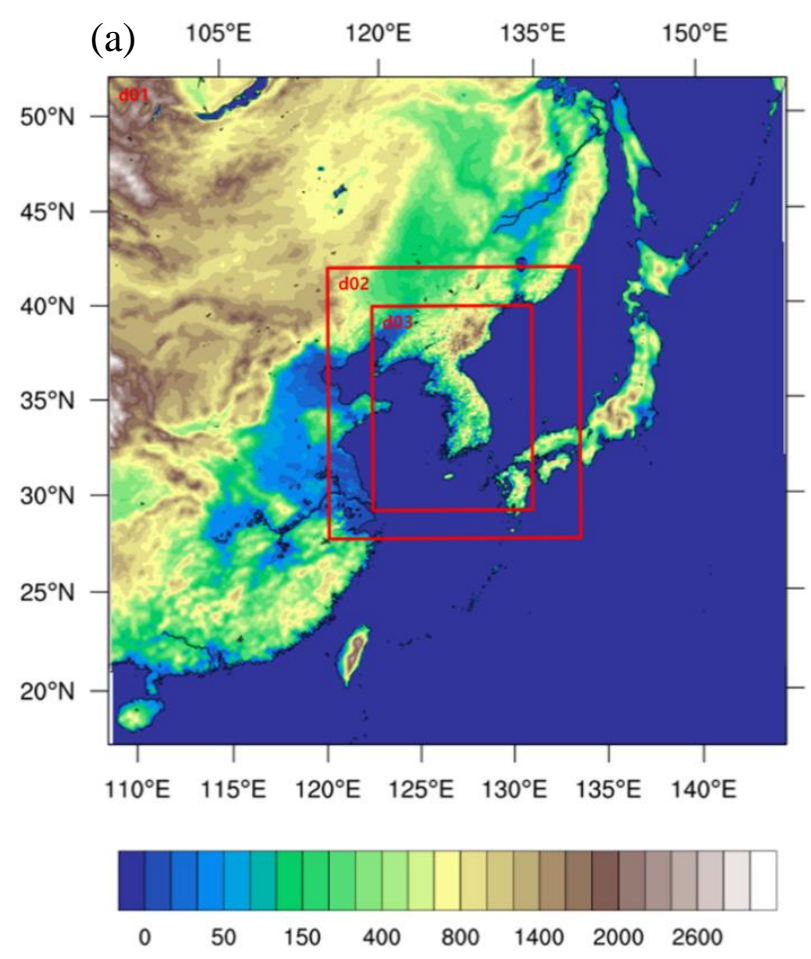

(b)

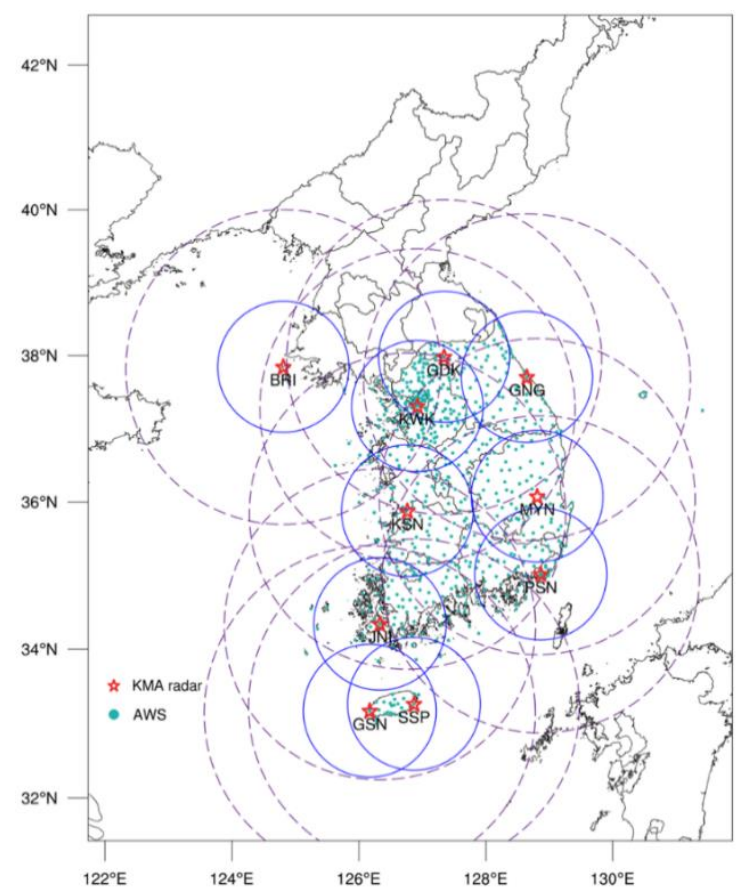

(c)

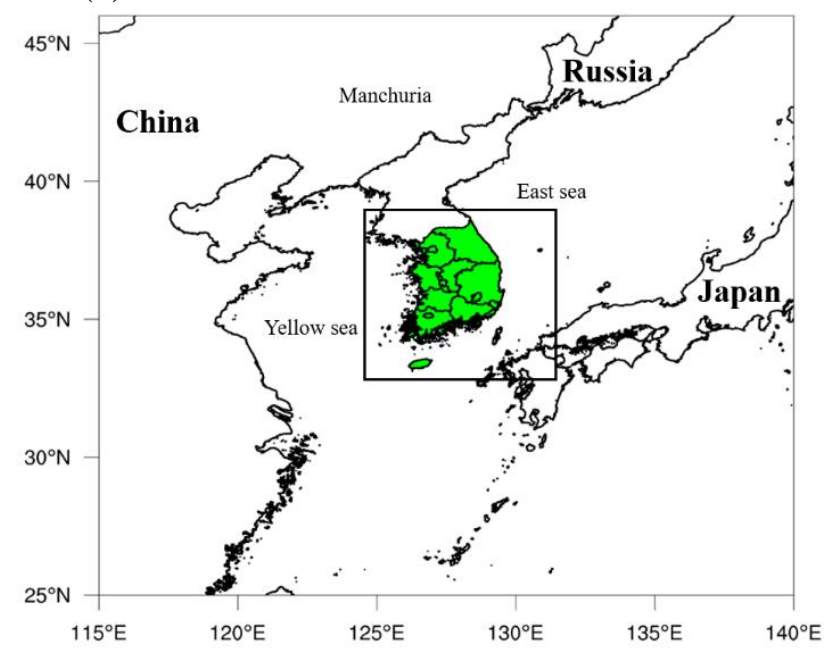

(d)

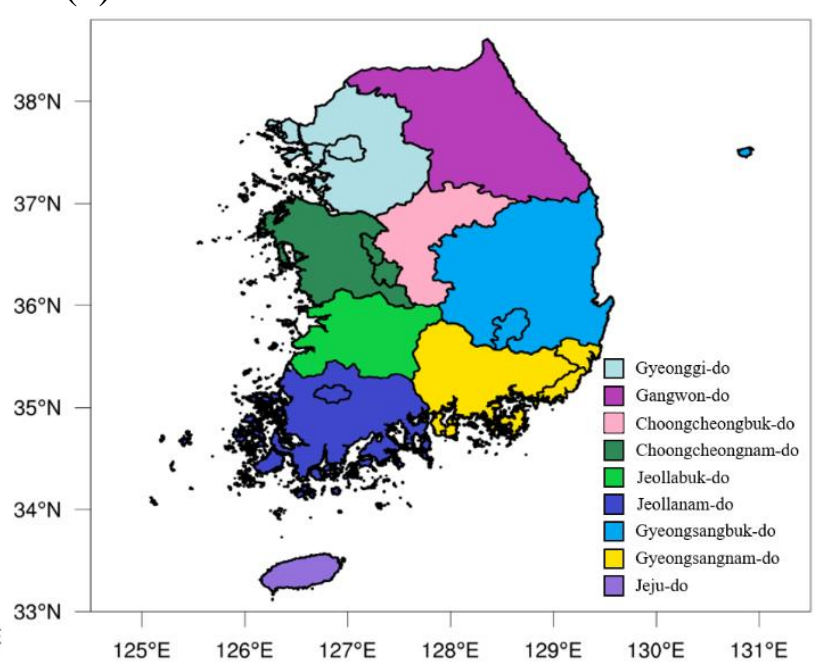

Figure 1. A map show (a) Nested domains of WRF model used in this study. Shading color indicates terrain height (meters), (b) Location of the observation site (red color makers are KMA radar sites and cyan color markers are KMA AWS sites), (c) Locacion of South Korea in the Eastern Asia, and (d) Provinces of South Korea., respectively. 
(a)

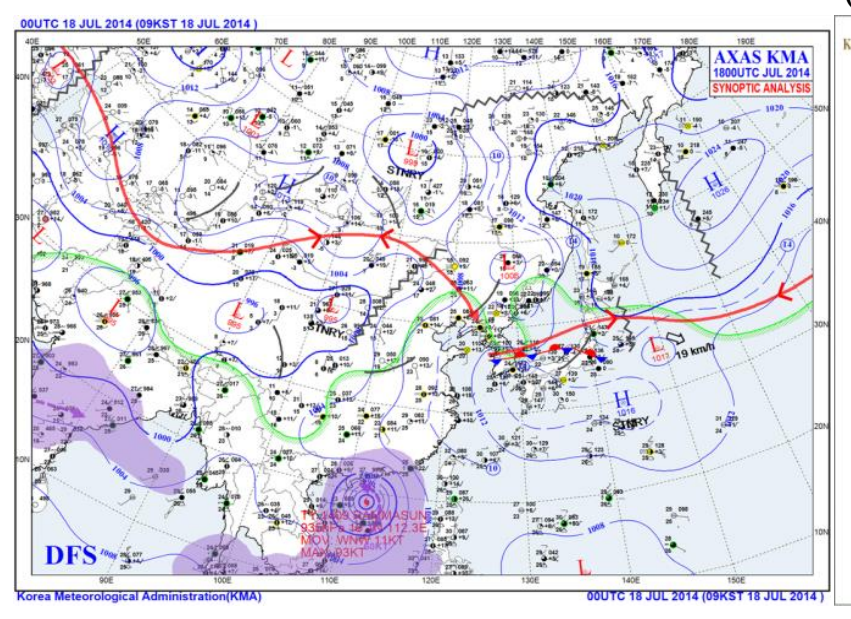

(b)

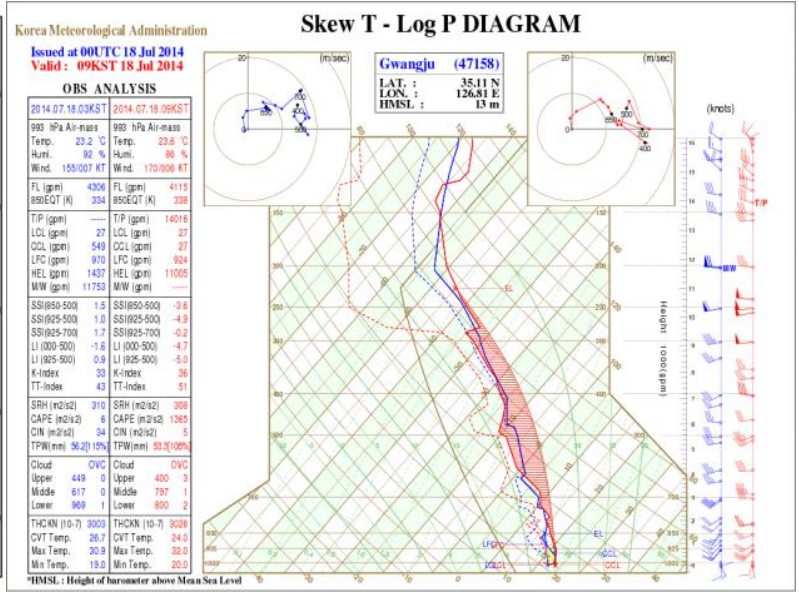

(c)

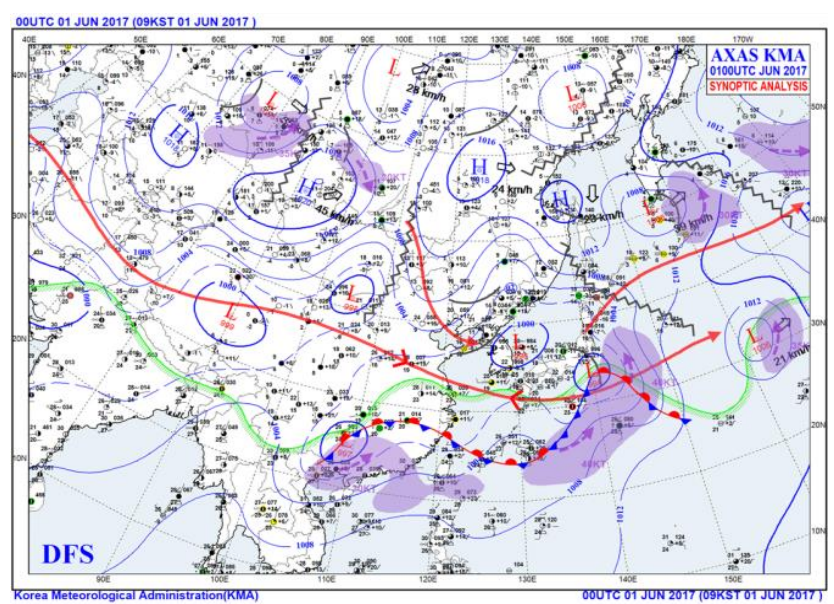

(d)

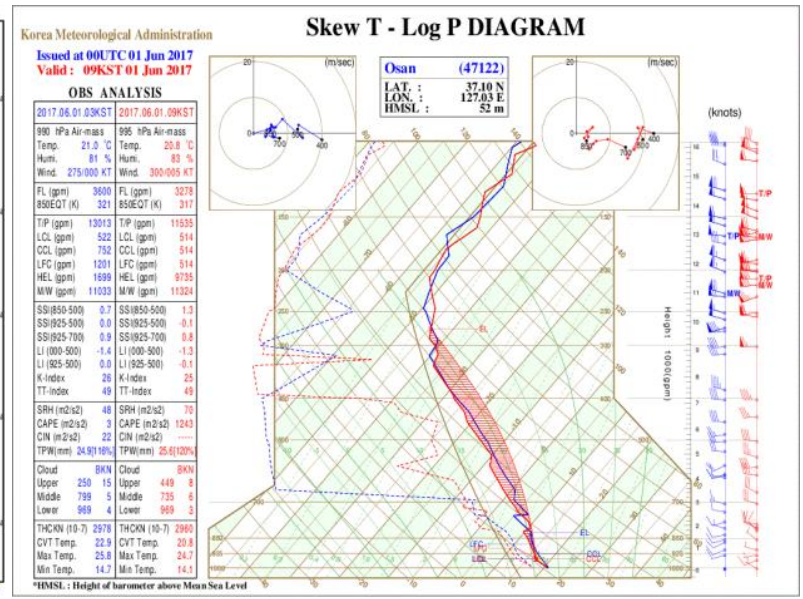

Figiure 2. Synoptic scale analysis for Meso 1 (upper panel; 0000 UTC 18 July 2014) and Meso 2 (bottom panel; 0000 UTC 01 June 2017). (a, c) Synthesis weather chart, and (b, d) skew T $-\log P$ diagram. Skew T - Log P diagram of the upper panel is Gwang-ju, and bottom panel is Osan observation site. 
(a)

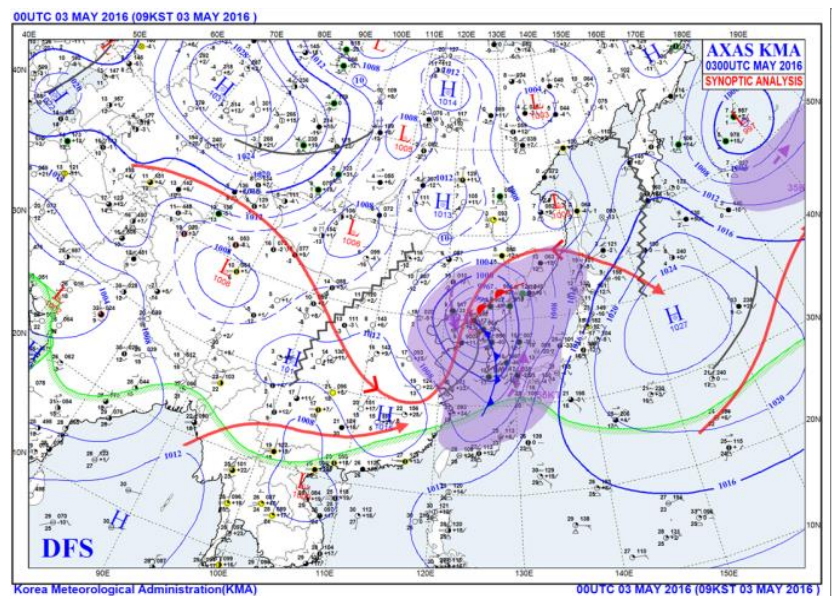

(b)

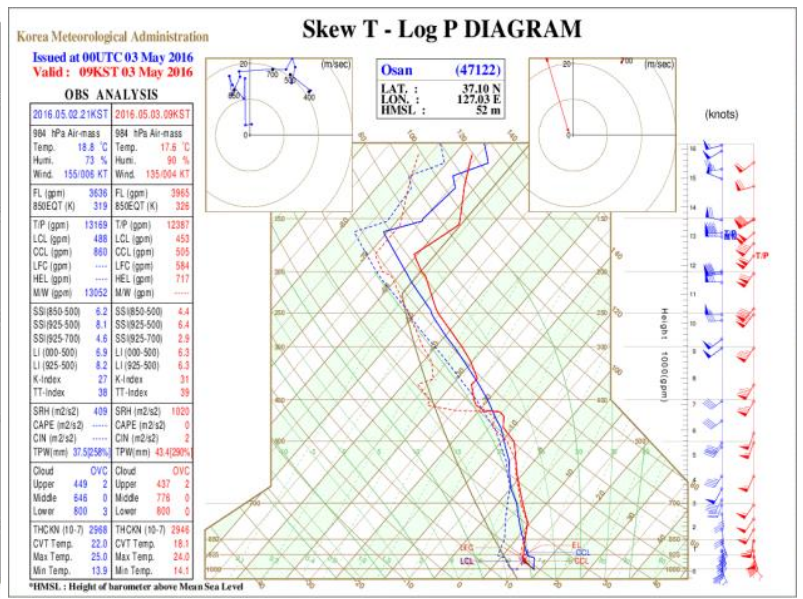

(c)

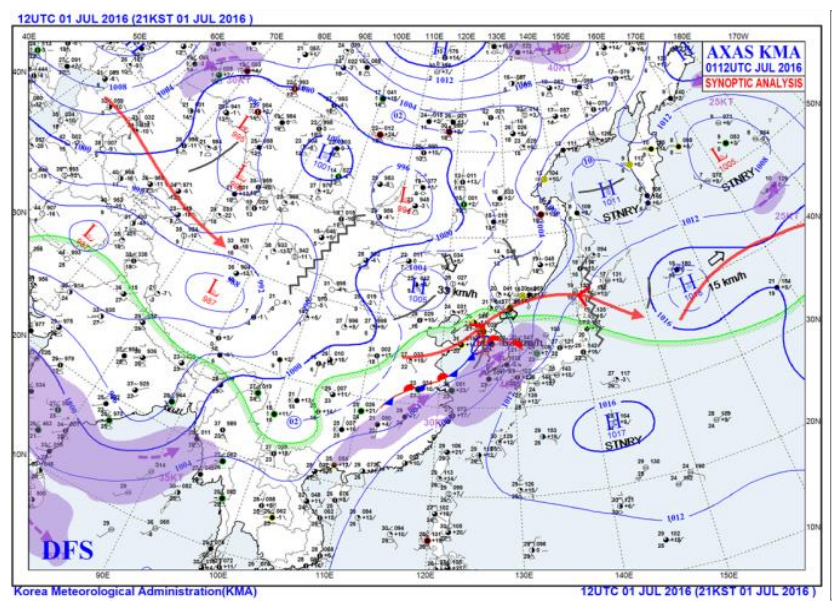

(d)

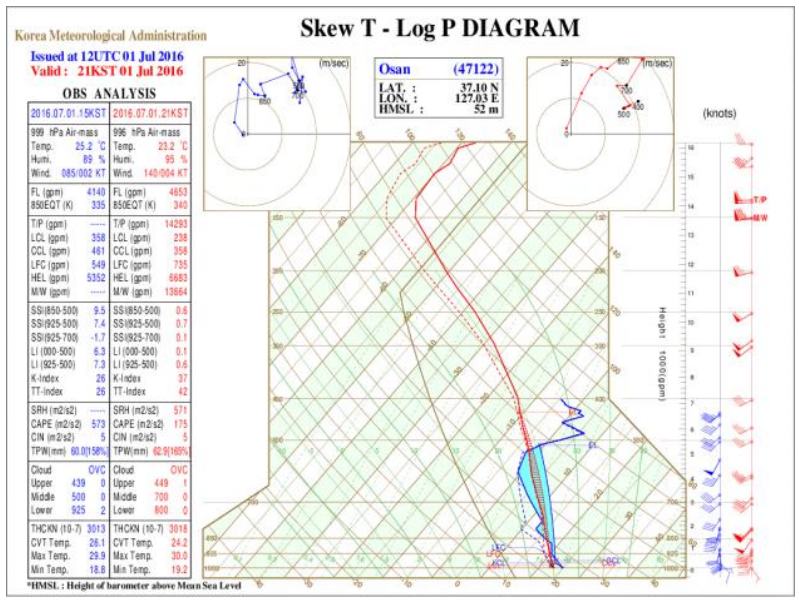

Figure 3. Same as Figure 2 but for Synop 1 (upper panel; 0000 UTC 03 May 2016, Osan) and Synop 2 (bottum panel; 1200 UTC 01 July 2016, Osan). 

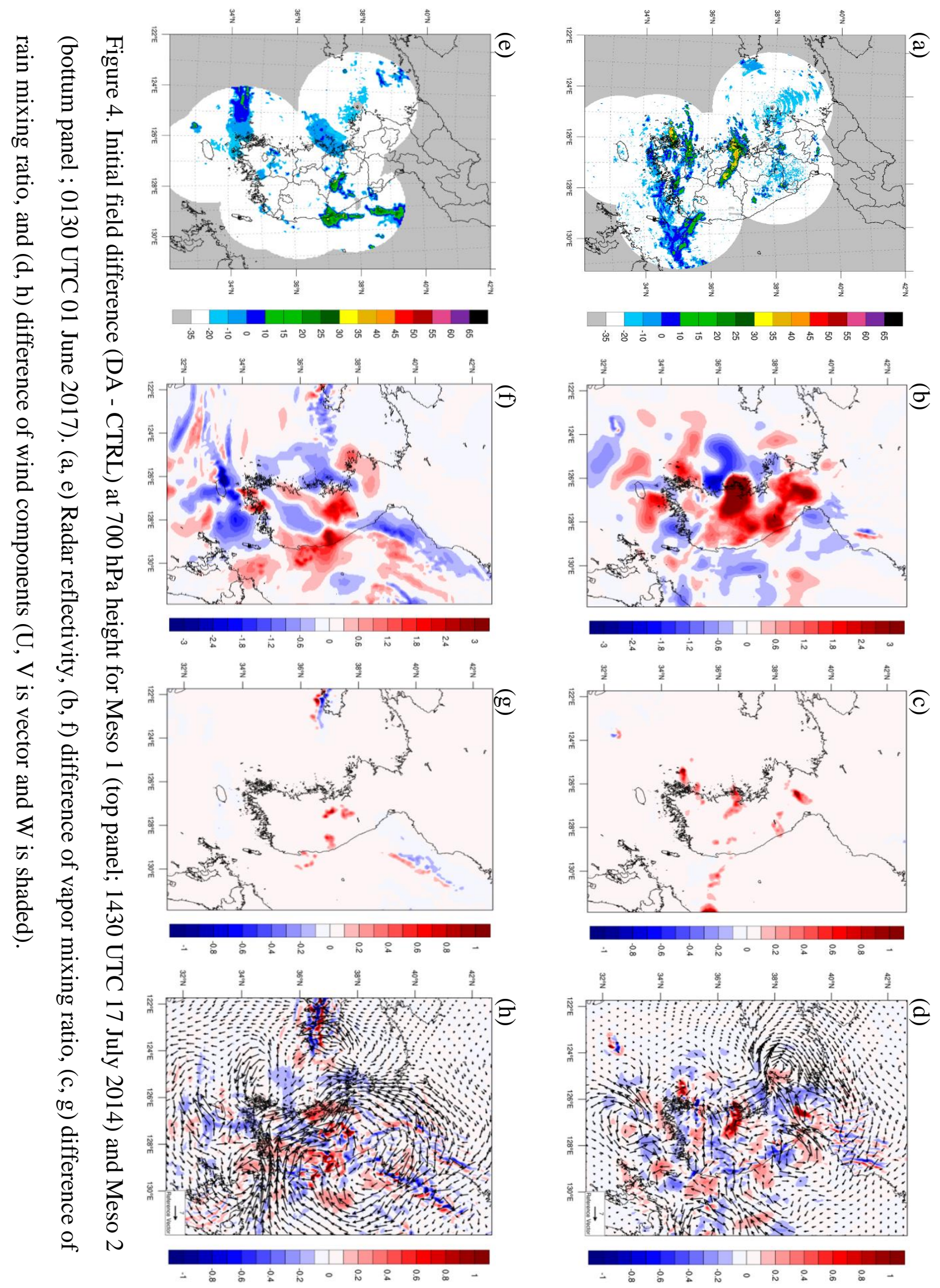


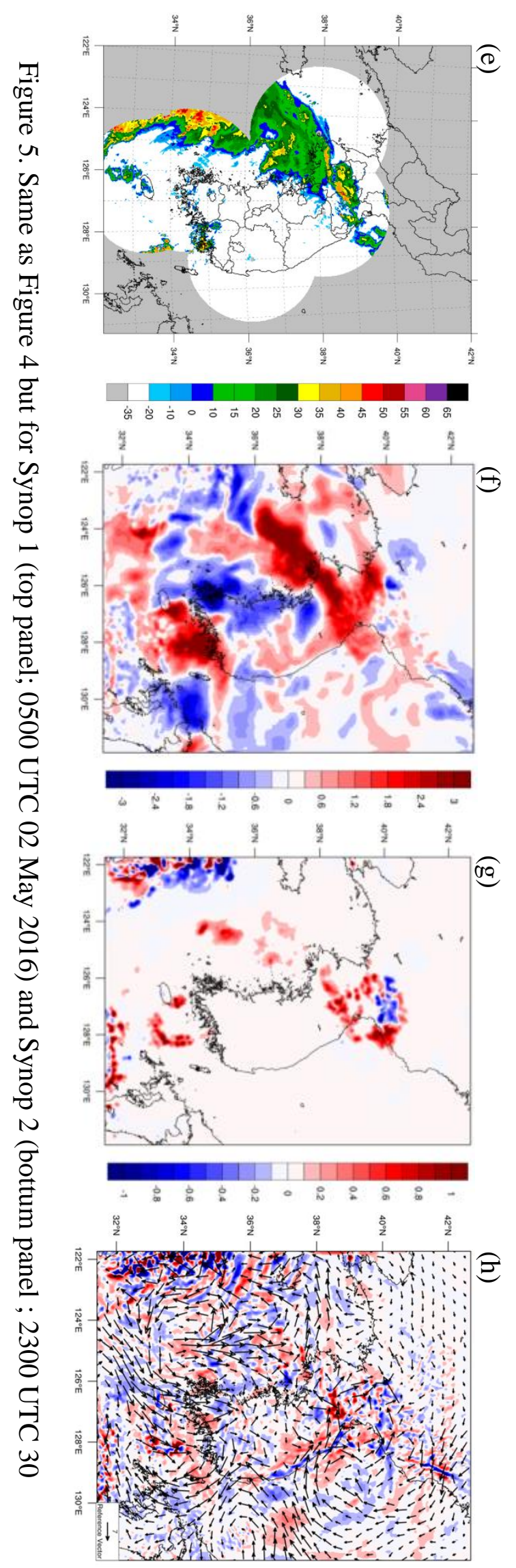

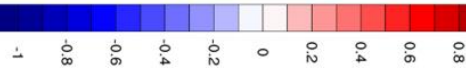

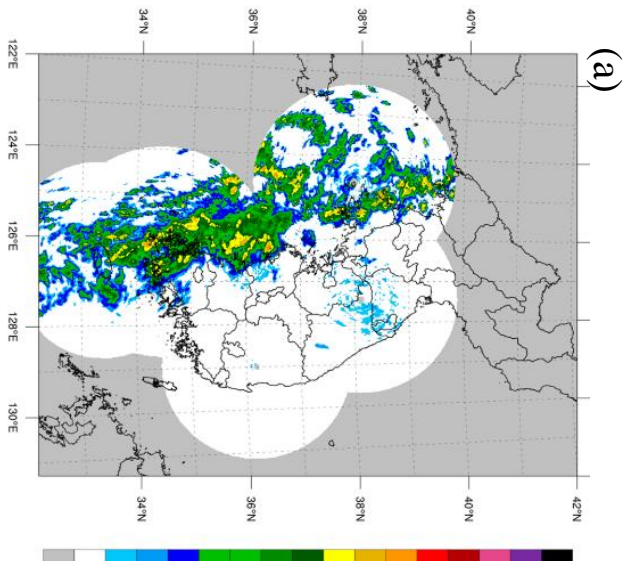

乡 ரे

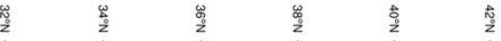
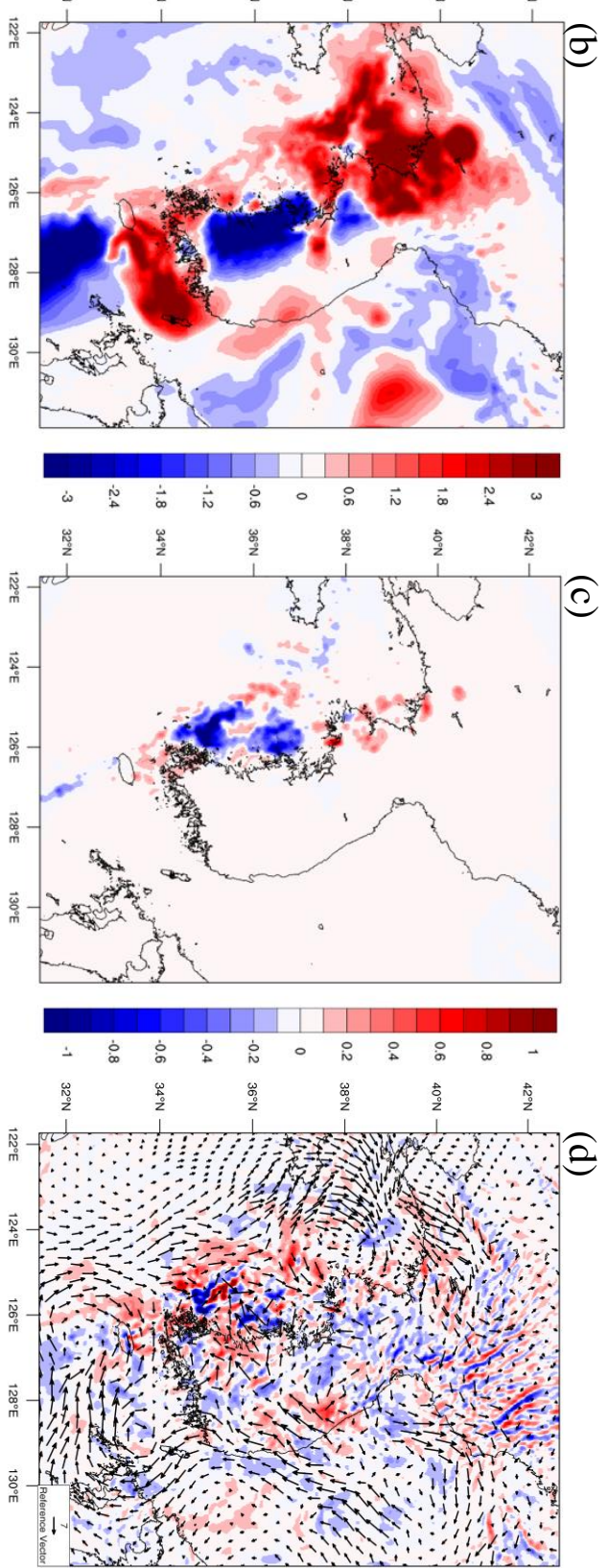

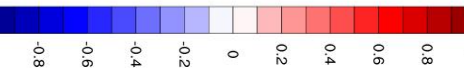




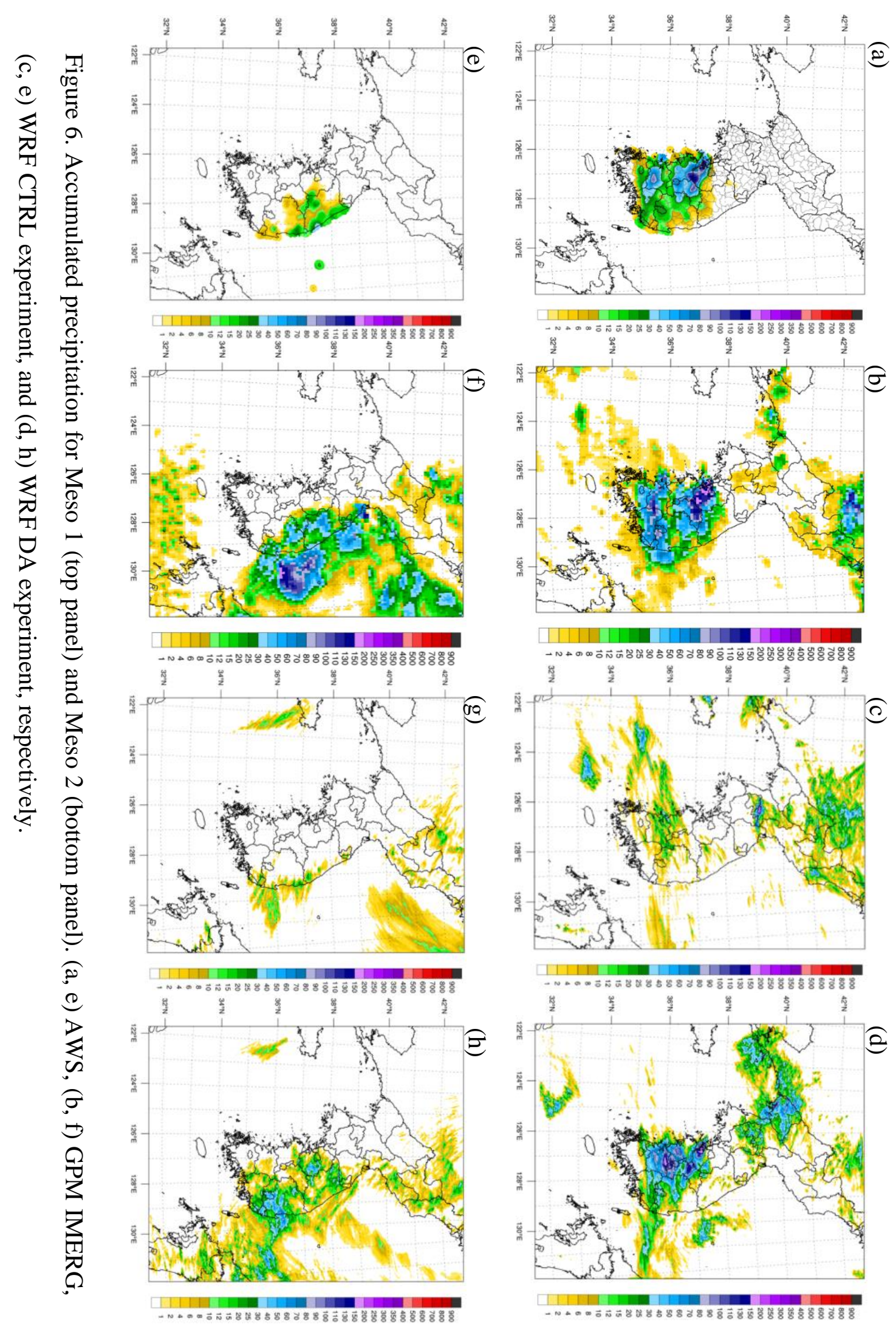




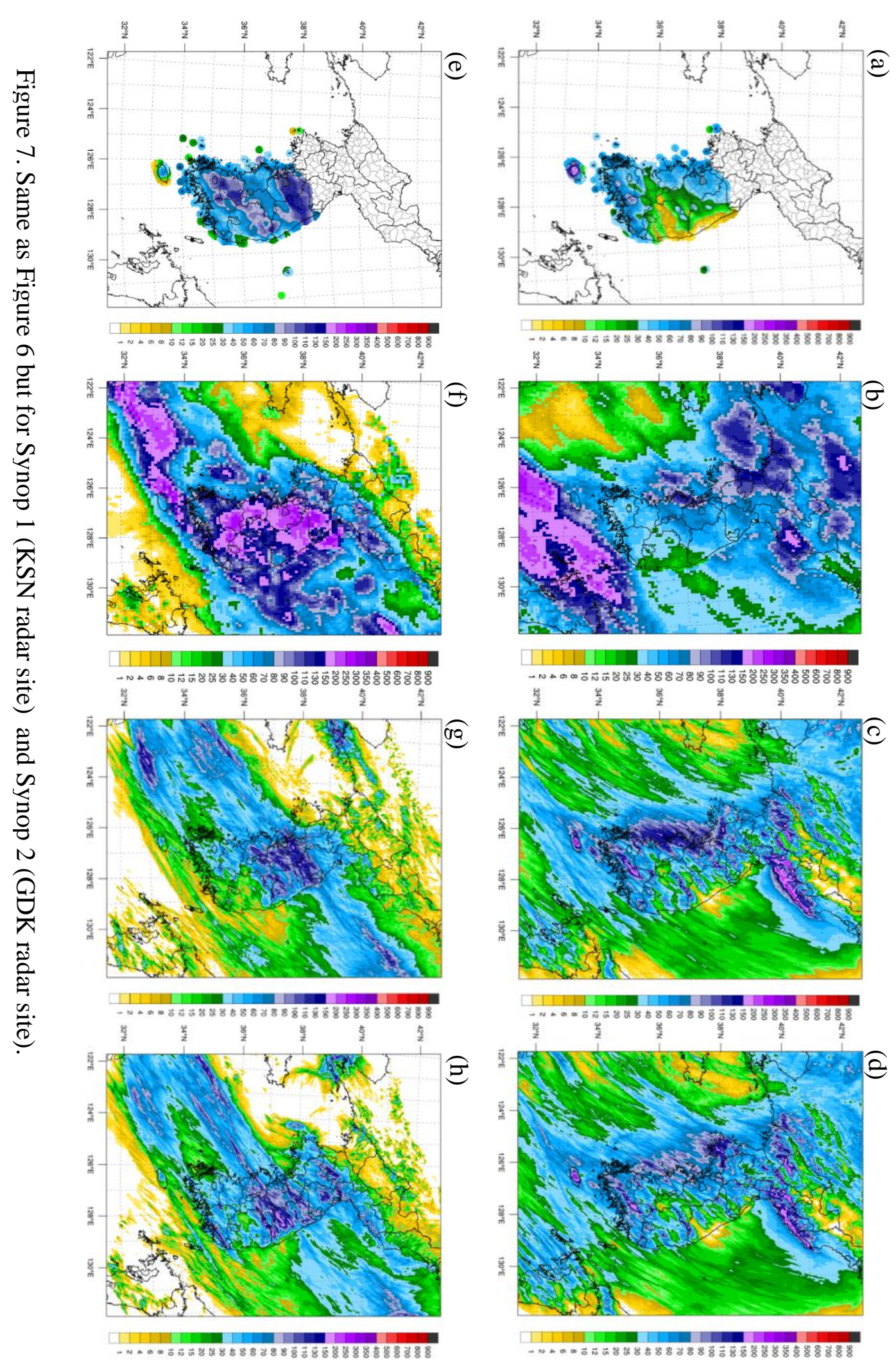



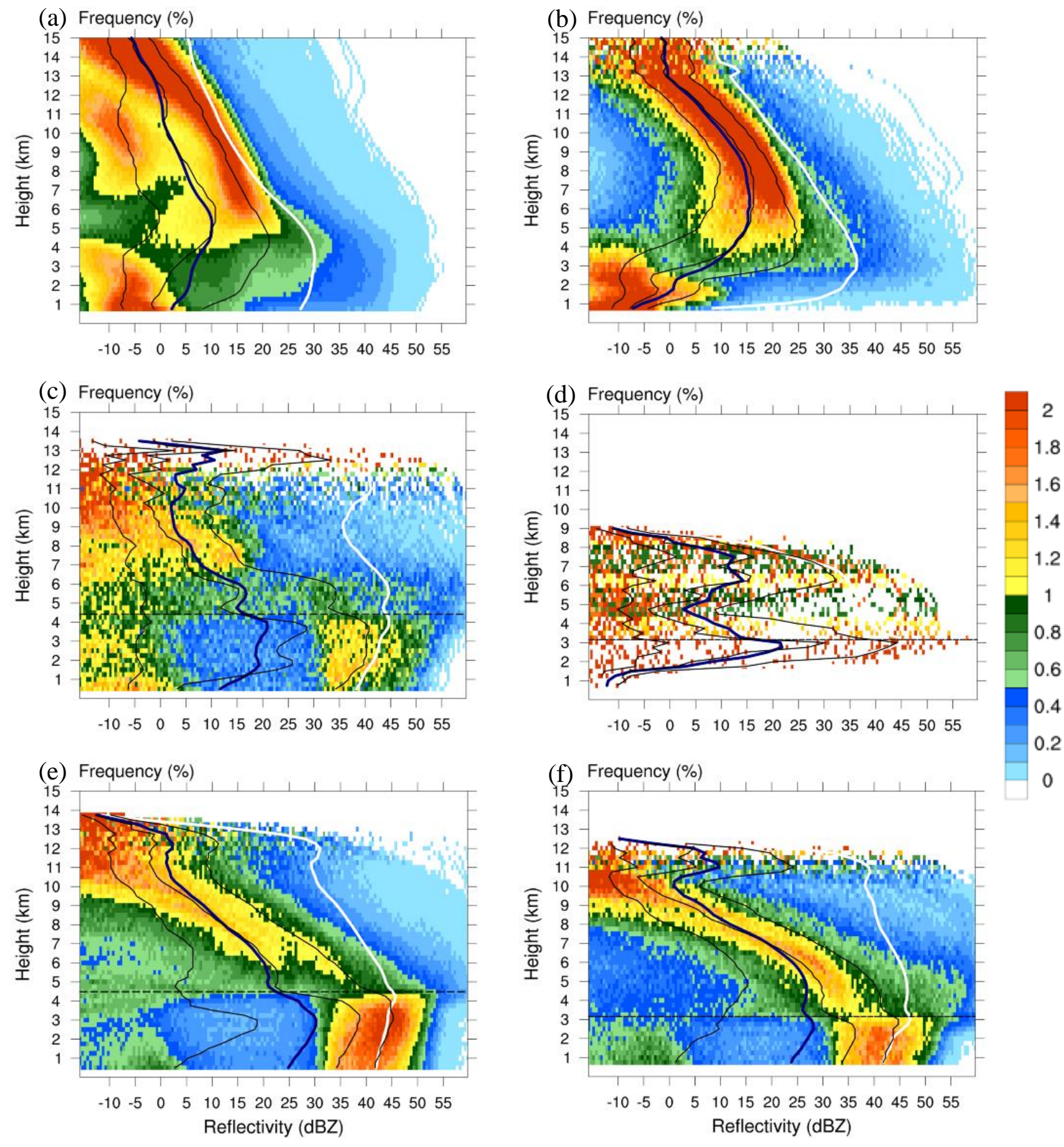

Figure 8. Averaged CFAD for Meso 1 and Meso 2 periods. (a, b) Radar observation, (c, d) WRF CTRL experiment, and (e, f) WRF DA experiment. left panal (a, c, e) is KSN radar site and right panal $(b, d, f)$ is $\mathrm{KWK}$ radar site. 


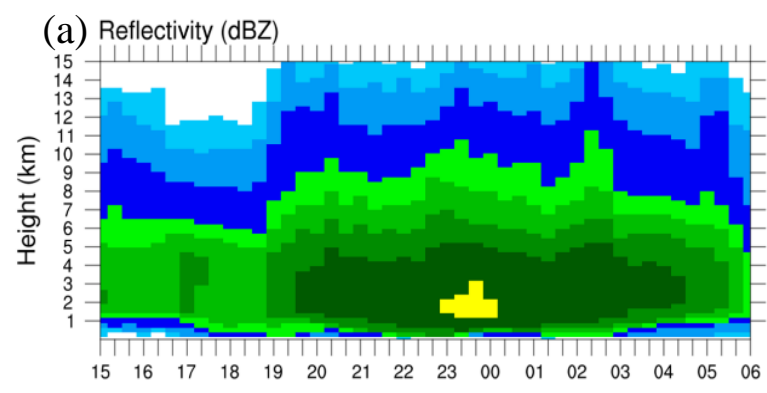

(b) Reflectivity (dBZ)

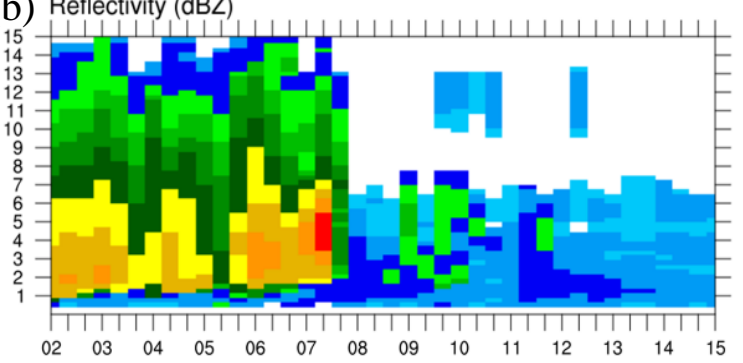

(c) Reflectivity (dBZ)

(d) Reflectivity (dBZ)
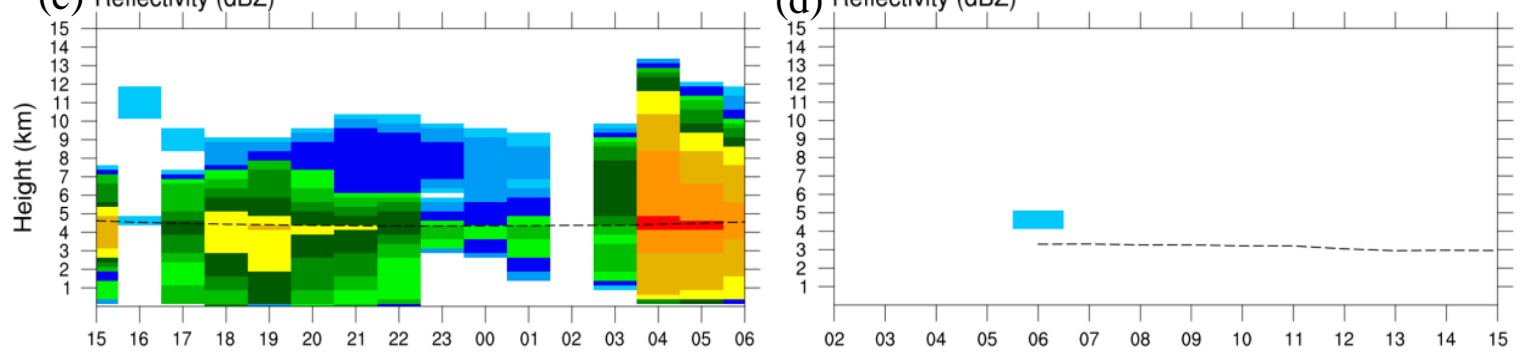

(e) Reflectivity (dBZ)

(f) Reflectivity (dBZ)
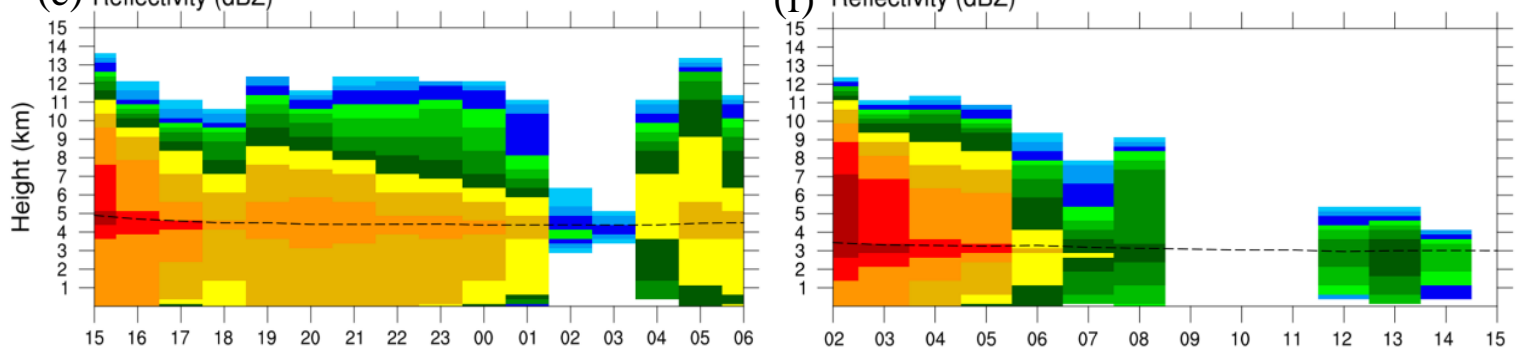

Figure 9. THCS for Meso 1 and Meso 2 periods. (a, b) Radar observation, (c, d) WRF CTRL experiment, and (e, f) WRF DA experiment. left panal (a, c, e) is KSN radar site and right panal (b, d, f) is KWK radar site. 

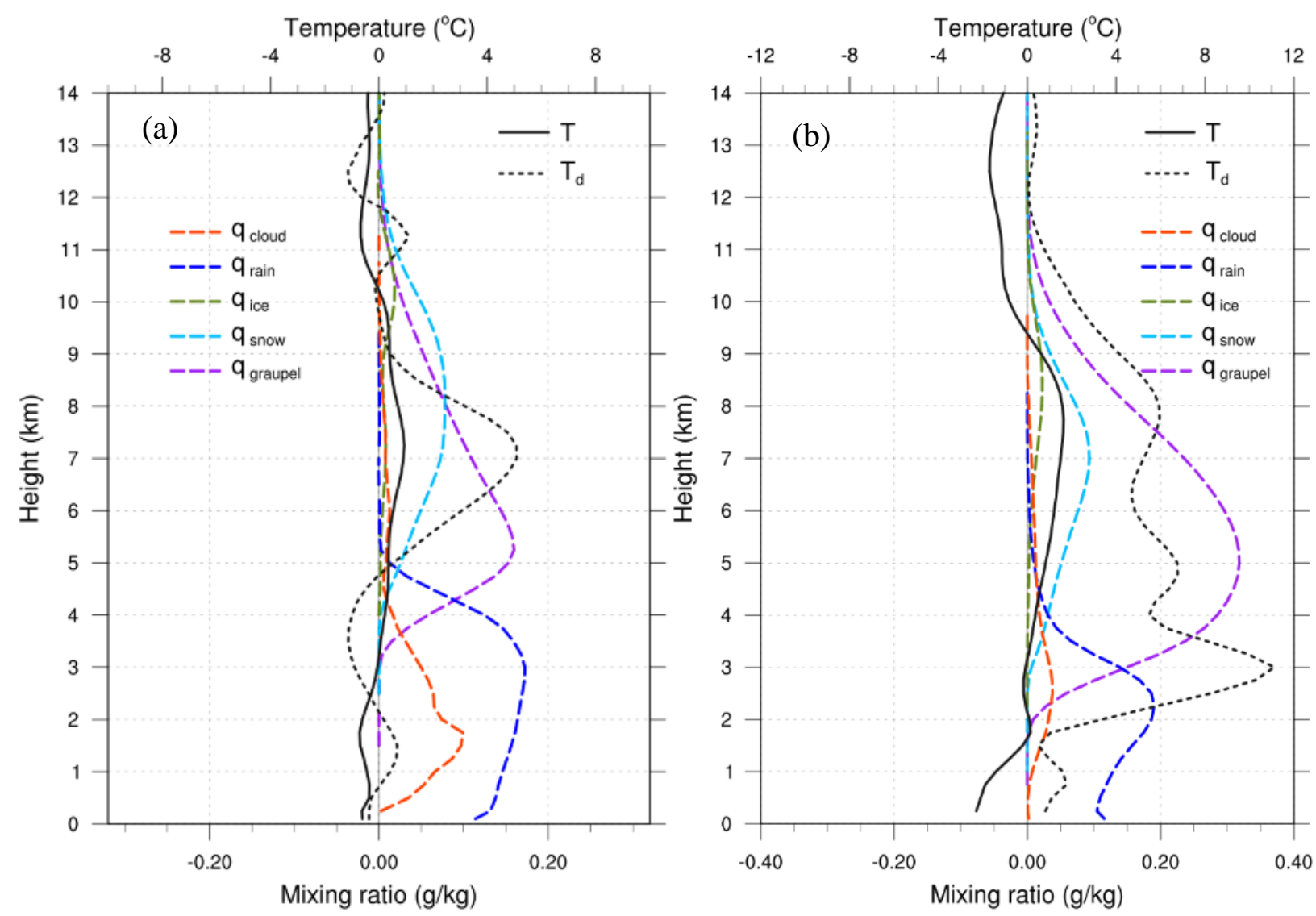

Figure 10. Difference of vertical hydrometeor profiles for all cases. Black line is temperature (solid) and dew-point temperature profile (dashed). Other colors are hydrometeor profiles (orange, $q_{\text {cloud }}$; blue, $q_{\text {rain }}$; green, $q_{\text {ice }}$; cyan, $q_{\text {snow }}$; pupple, $q_{\text {graupel }}$ ). (a) Meso 1 (KSN radar site) and (b) Meso 2 (KWK radar site). 

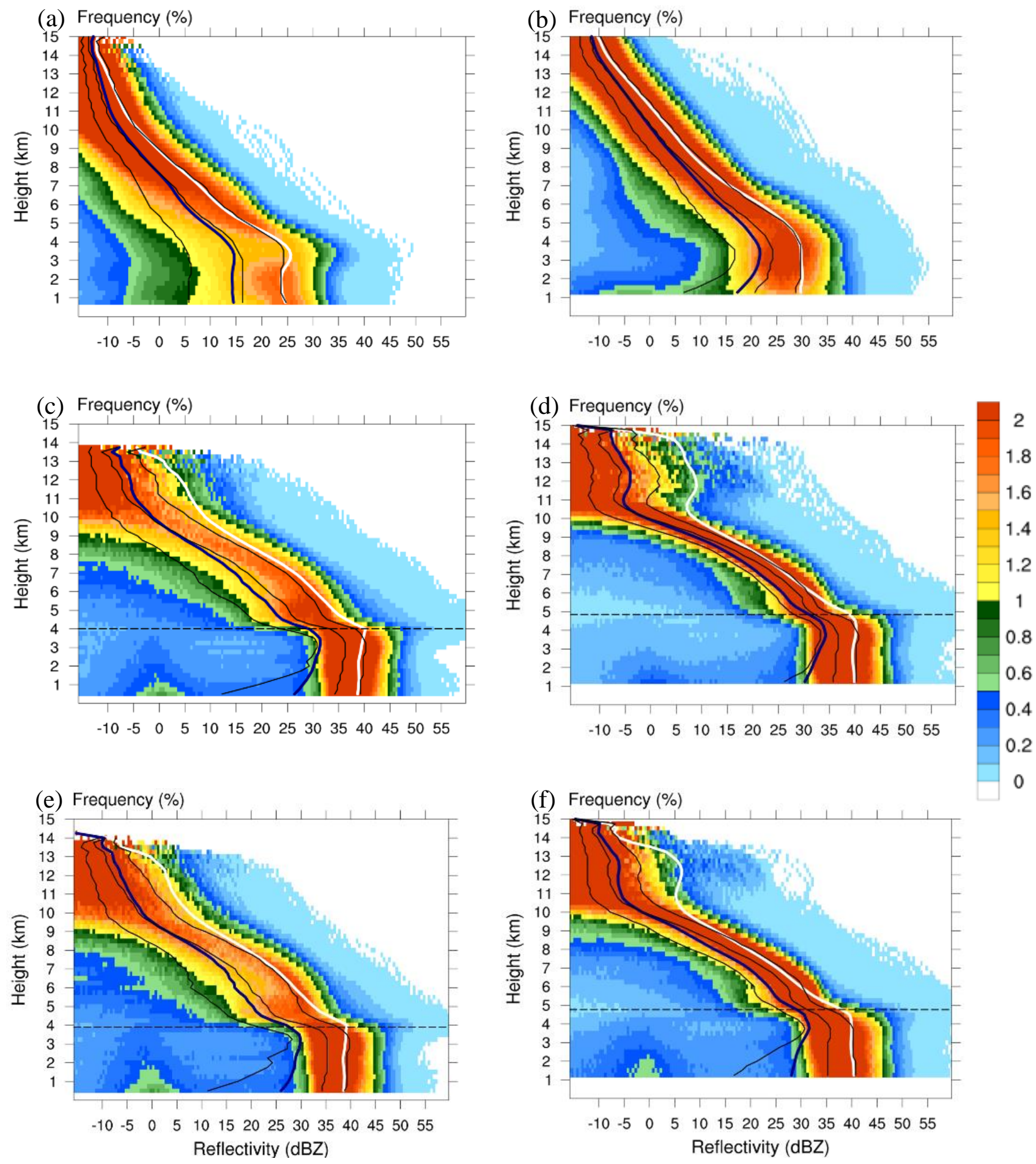

Figure 11. Same as Figure 8 but for Synop 1 (KSN radar site) and Synop 2 (GDK radar site). 
(a) Reflectivity (dBZ)

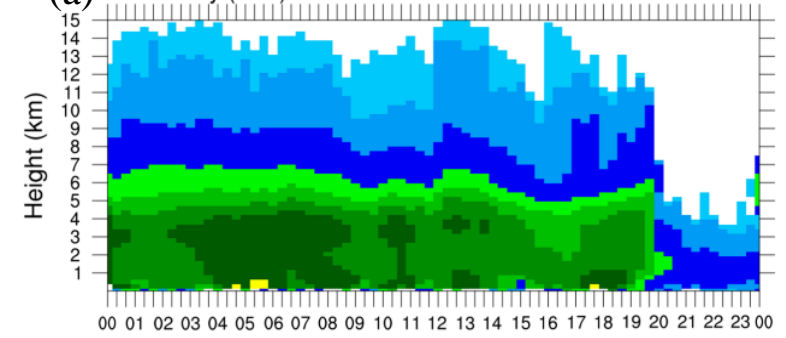

(c) Reflectivity (dBZ)

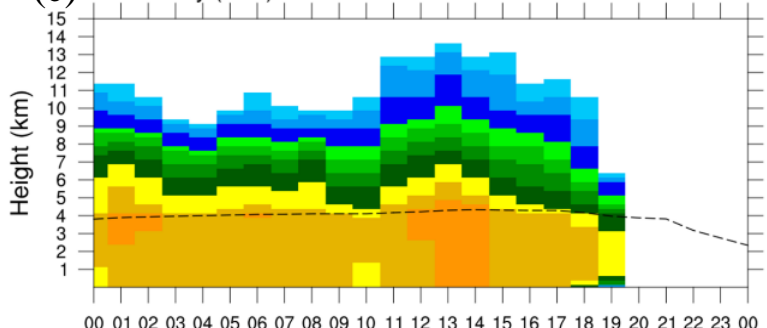

(e) Reflectivity (dBZ)

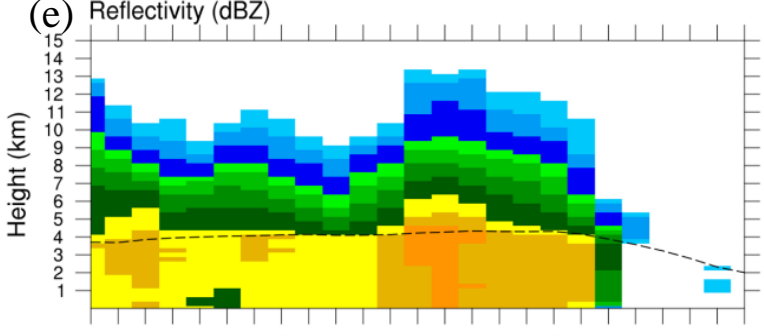

00010203040506070809101112131415161718192021222300 (b) Reflectivity (dBZ)

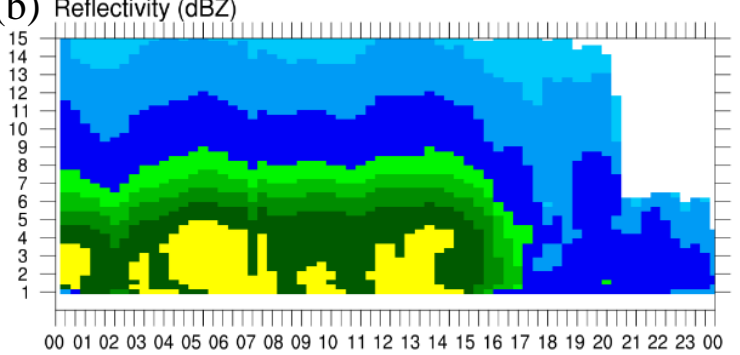

(d) Reflectivity (dBZ)

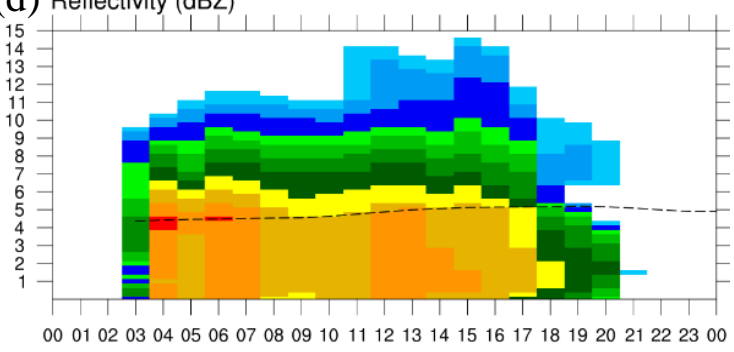

(f) Reflectivity (dBZ)

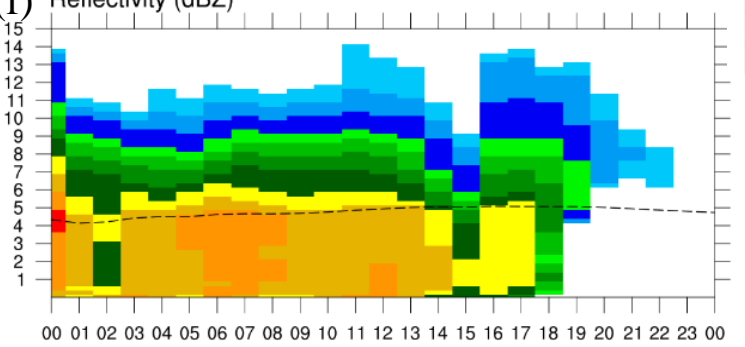

Figure 12. Same as Figure 9 but for Synop 1 (KSN radar site) and Synop 2 (GDK radar site). 

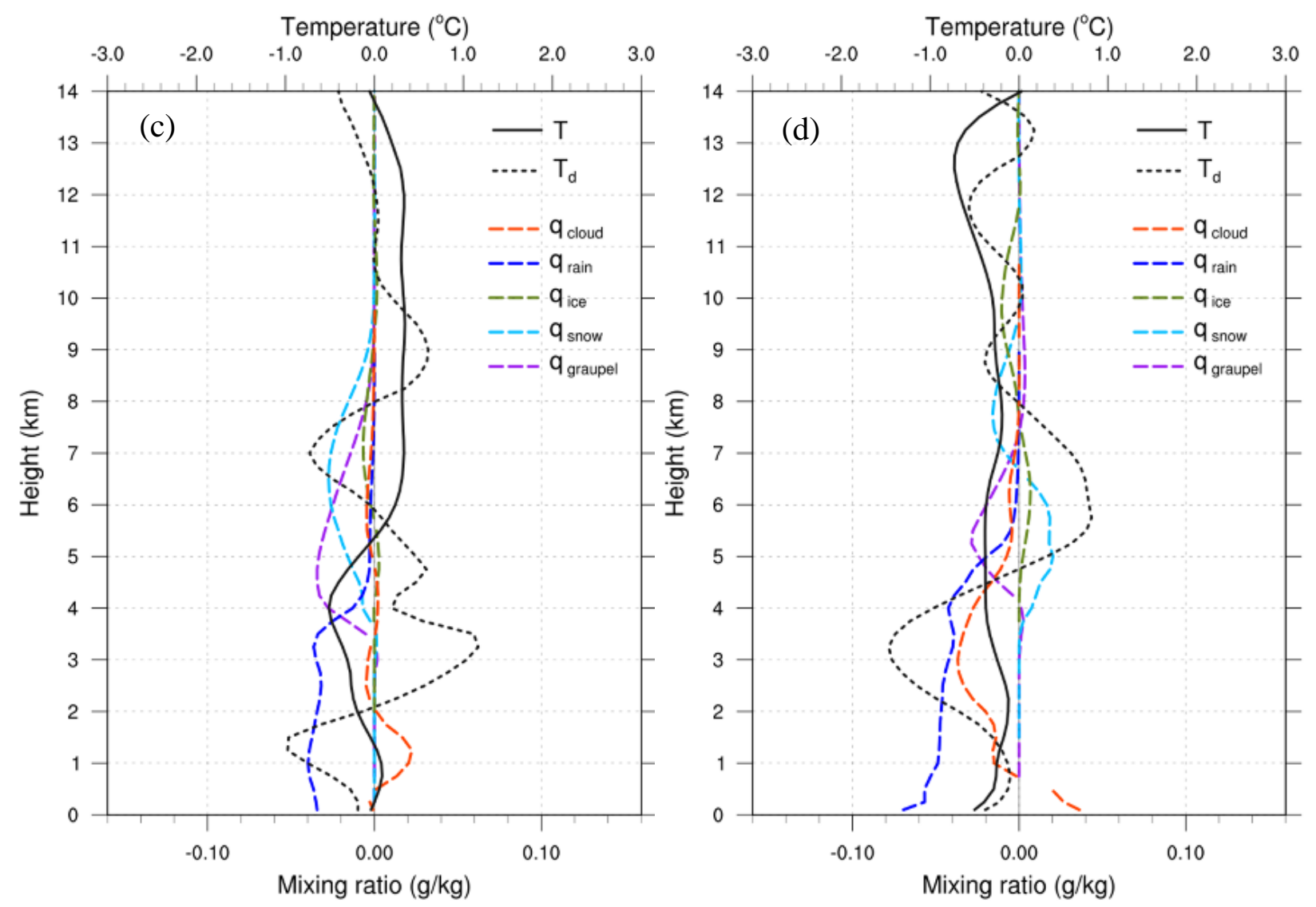

Figure 13. Same as Figure 10 but for Synop 1 (KSN radar site) and Synop 2 (GDK radar site). 


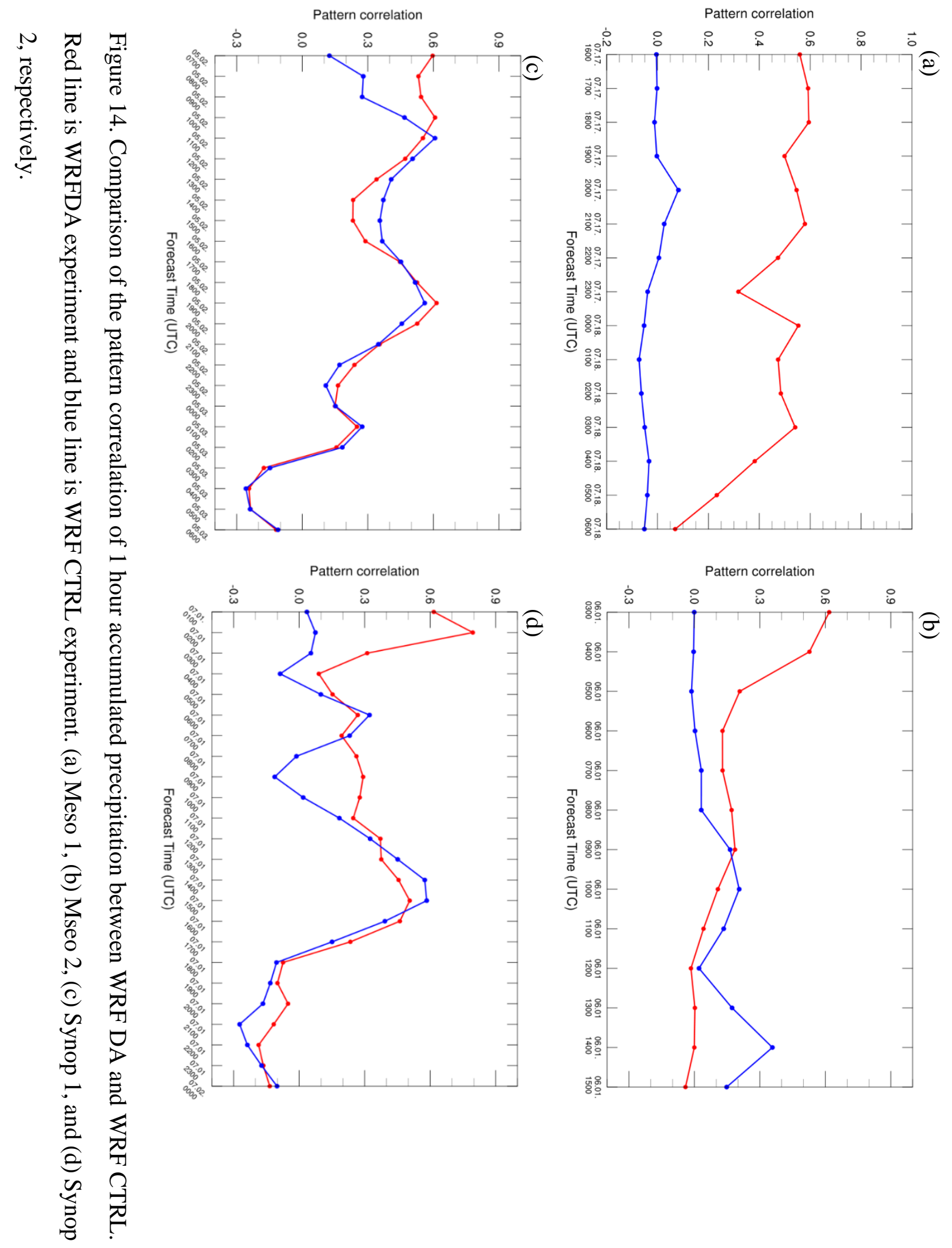

